Marine Geophysical Research

June 2018, Volume 39 Issue 1-2 Pages 151-168

http://dx.doi.org/10.1007/s11001-018-9346-7

Archimer

http://archimer.ifremer.fr/doc/00429/54018/

(C) This is a U.S. Government work and not under copyright protection in

the US; foreign copyright protection may apply 2018

\title{
A framework to quantify uncertainties of seafloor backscatter from swath mapping echosounders
}

\author{
Malik Mashkoor ${ }^{1,3,{ }^{*}}$, Lurton Xavier ${ }^{2}$, Mayer Larry ${ }^{3}$
}

\author{
${ }^{1}$ NOAA, Off Ocean Explorat \& Res, Silver Spring, MD 20910 USA. \\ 2 Inst Francais Rech Exploitat Mer IFREMER, Underwater Acoust Lab IMN NSE ASTI, Plouzane, \\ France. \\ ${ }^{3}$ Univ New Hampshire, Ctr Coastal \& Ocean Mapping, Joint Hydrog Ctr, Durham, NH 03824 USA. \\ *Corresponding author : Mashkoor Malik, email address : Mashkoor.Malik@noaa.gov
}

\begin{abstract}
:
Multibeam echosounders (MBES) have become a widely used acoustic remote sensing tool to map and study the seafloor, providing co-located bathymetry and seafloor backscatter. Although the uncertainty associated with MBES-derived bathymetric data has been studied extensively, the question of backscatter uncertainty has been addressed only minimally and hinders the quantitative use of MBES seafloor backscatter. This paper explores approaches to identifying uncertainty sources associated with MBES-derived backscatter measurements. The major sources of uncertainty are catalogued and the magnitudes of their relative contributions to the backscatter uncertainty budget are evaluated. These major uncertainty sources include seafloor insonified area (1-3 dB), absorption coefficient (up to $>6$ $\mathrm{dB}$ ), random fluctuations in echo level (5.5 dB for a Rayleigh distribution), and sonar calibration (device dependent). The magnitudes of these uncertainty sources vary based on how these effects are compensated for during data acquisition and processing. Various cases (no compensation, partial compensation and full compensation) for seafloor insonified area, transmission losses and random fluctuations were modeled to estimate their uncertainties in different scenarios. Uncertainty related to the seafloor insonified area can be reduced significantly by accounting for seafloor slope during backscatter processing while transmission losses can be constrained by collecting full water column absorption coefficient profiles (temperature and salinity profiles). To reduce random fluctuations to below $1 \mathrm{~dB}$, at least 20 samples are recommended to be used while computing mean values. The estimation of uncertainty in backscatter measurements is constrained by the fact that not all instrumental components are characterized and documented sufficiently for commercially available MBES. Further involvement from manufacturers in providing this essential information is critically required.
\end{abstract}

Keywords : Multibeam echosounder, Calibration, Incidence angle 


\section{Introduction}

Amongst acoustic sensors, multibeam echosounders (MBES) are commonly the tool of choice for most seafloor studies because they concurrently offer high-resolution, co-located bathymetry and backscatter (Hughes Clarke et al. 1996; Mayer 2006; Anderson et al. 2007; Lucieer et al. 2017). Historically the analysis of multibeam sonar data has focused on the bathymetric component and the critical role it plays in nautical charting and in offering insights into geologic and tectonic processes of the seafloor. The rich history of the use of MBES for critical mapping applications has resulted in significant progress over the last two decades in quantifying the sources of uncertainty associated with the bathymetric component of MBES (Hare et al. 1995; Hare 2001; Calder and Mayer 2003; Lurton and Augustin 2010; Lucieer et al. 2015) adding tremendously to the credibility and value of bathymetric data.

More recently, the interpretation of the second component of MBES systems, namely seafloor backscatter, is playing an increasingly important role in many ocean-mapping applications including habitat characterization, environmental monitoring, geological and geotechnical studies, and natural resource prospecting (Lucieer et al. 2017). In support of these applications, efforts have been made to use MBES backscatter to characterize the nature of the seafloor, typically through broad descriptions of seafloor or sediment type (e.g. rock, sand, mud) or in other instances, to further estimate basic parameters like grain size or acoustic properties (Hasan et al. 2014 and references therein). Unlike for bathymetry, however, there has been little efforts made to understand the uncertainty associated with MBES backscatter measurements and thus methods of seafloor characterization using backscatter are not constrained with respect to associated uncertainty.

The interpretation of backscatter data for seafloor characterization is typically done through the analysis of backscatter mosaic texture or seafloor backscatter angular response. The backscatter mosaic is a georeferenced image of the signal intensity scattered back to the sonar. With different seafloor materials showing different intensity levels, mosaics can be used to segment the seafloor into different types either subjectively by an interpreter, or more objectively through image processing approaches (e.g. Reed and Hussong 1989; Brown et al. 2011; Diesing et al. 2016). As the echo intensity varies with the angle of incidence of the acoustic signal at the seafloor, the angular variations of backscatter have to be normalized (typically at $45^{\circ}$ ) for the mosaic to be interpretable. As a result of this normalization process, a key quantitative aspect of the seafloor properties (its angular response) is lost, hence limiting the use of mosaics to qualitative interpretation (Schimel et al. 2015). Even when viewed qualitatively, the lack of knowledge of the uncertainty associated with the backscatter levels depicted on a mosaic calls into question the meaning of the interpretation. Issues of uncertainty in seafloor backscatter measurements have become apparent when combining and comparing data sets from different MBES surveys (e.g., Hughes Clarke 2012; Lacharité et al. 2017) where surveys from different systems resulted in wildly different backscatter results. 
Unlike the backscatter mosaic, the analysis of the backscatter angular response allows for the extraction of quantitative features and algorithm-based seafloor characterization approaches (e.g., Fonseca and Mayer 2007). Such approaches can provide useful predictions of seafloor type provided that uncertainties are appropriately constrained (Fonseca et al. 2009; Rzhanov et al. 2012; Hasan et al. 2014) but suffer from the current lack of understanding of uncertainties in the underlying backscatter measurements. With more emphasis on automated and physical model driven characterization techniques, quantification of backscatter data is becoming more important (Alevizos et al. 2017) involving efforts in MBES calibration, and in better understanding, modelling, and estimating the associated uncertainty.

The aim of this paper is to identify the major sources of uncertainty for MBES-derived seafloor backscatter values, evaluate (when possible) their causes and estimate their magnitudes. In doing so, we hope to establish a framework for further analyses that may be broadly applied to various systems and situations so that end-users and operators may aspire to a more quantitative understanding of seafloor backscatter. We begin with a review of the basics of seafloor backscatter measurements. We then seek to identify the significant sources of uncertainty and quantify their respective magnitudes. Finally suggestions are made that might help mitigate the major sources of uncertainty.

\section{Preliminary notions}

\subsection{Elements of backscatter measurement}

MBES backscatter data result from the measurements of seafloor target strength (see e.g. Urick 1983), a quantity that relates the incident and scattered pressure fields from a given target - in our case a small patch of the seafloor instantaneously insonified by the sonar signal. The ensemble average of squared scattered pressure $\left\langle\left|p_{s}\right|^{2}\right\rangle$ is proportional to the insonified area $A$ and the squared incident pressure $\left|p_{i}\right|^{2}$, and inversely proportional to the sonar-target squared distance $r_{s}^{2}$, neglecting absorption and refraction effects:

$$
\left\langle\left|p_{s}\right|^{2}\right\rangle=\left|p_{i}\right|^{2} A \sigma_{b} \frac{1}{r_{s}^{2}}
$$

where the proportionality coefficient $\sigma_{b}$ is referred to as the "backscattering cross-section per unit area per unit solid angle" (Jackson and Richardson 2007 p 23); its logarithmic equivalent is the "bottom scattering strength" (Urick 1983):

$$
S_{b}=10 \log _{10} \sigma_{b} .
$$

The target strength (TS in $\mathrm{dB}$ re $1 \mathrm{~m}^{2}$ ) of the seafloor area $A$ is then related to the scattering strength by:

$$
T S=S_{b}+10 \log _{10} A .
$$


$10 \log _{10} A$ is used here instead of the correct form $10 \log _{10}\left(A / A_{0}\right)$ for notation simplicity where $A_{0}$ $=1 \mathrm{~m}^{2}$ is the reference unit surface. In the practical situation where TS is measured by a directional transmitter and receiver, the mean square voltage at the receiver output is expressed in $\mathrm{dB}$ as:

$10 \log _{10}\left[\left\langle\left|V_{r(t)}\right|^{2}\right\rangle\right]=E L+R S_{o}=S L_{o}+D_{T X}-2 T L+10 \log _{10} A+S_{b}+R S_{o}+D_{R X} \quad$ [Eq. 4]

where $\left\langle\left|V_{r(t)}\right|^{2}\right\rangle$ is the average squared voltage at receiver, EL the echo level at the receiver, $R S_{o}$ the sensitivity of the receiver transforming the incident acoustic pressure into an electrical signal along its maximum response axis, $S L_{o}$ the source level along its maximum response axis, $2 T L$ the two-way transmission loss, $A$ the insonified area, $D_{T X}$ and $D_{R X}$ the transmit $(T x)$ and receive $(R x)$ directivity function values in the sonar-target propagation direction (Lurton 2010). The received voltage is then converted to a digital number $D N$ through an Analog-to-Digital Converter (ADC) and recorded; this operation introduces a specific offset $G_{A D}$ so that:

$$
D N=10 \log _{10}\left[\left\langle\left|V_{r(t)}\right|^{2}\right\rangle\right]+G_{A D} .
$$

The value of $G_{A D}$ is related to how the digitization process is carried out, including the ADC's technological characteristics (Schimel et al. 2015). The measured backscatter strength can then be expressed from [Eq. 4] and [Eq. 5] as:

$$
S_{b}=D N-R S_{o}-G_{A D}-S L_{o}+2 T L-D_{T X}-D_{R X}-10 \log _{10} A .
$$

For a given seafloor type and frequency, this value of $S_{b}$ is also related to the seafloor incidence angle $\theta$. The various uncertainty sources contributing to the measured $S_{b}$ and $\theta$ are analyzed in the rest of this paper. In the following the $S_{b}$ uncertainty expressed in $\mathrm{dB}$ relates to the percentage uncertainty in $\sigma_{b}$; for example, a $1 \mathrm{~dB}$ uncertainty in $S_{b}$ relates to a $10 \%$ uncertainty in $\sigma_{b}$.

\subsection{Sources of seafloor backscatter measurement uncertainty}

The expression [Eq. 6] for seafloor backscatter strength can be grouped as:

$$
S_{b}=\left\{D N-R S_{o}-G_{A D}-S L_{o}-D_{T X}-D_{R X}\right\}+\{2 T L\}-\left\{10 \log _{10} A\right\}
$$

suggesting three main components of uncertainty:

1. The first component $\left\{D N-R S_{o}-G_{A D}-S L_{o}-D_{T X}-D_{R X}\right\}$ is the practical output of the target strength measurement, combining the measured echo level $(D N)$, the source level $\left(S L_{o}\right)$, the sonar $R x$ sensitivity $\left(R S_{o}\right.$ and $\left.G_{A D}\right)$ and directivity $\left(D_{T X}\right.$ and $\left.D_{R X}\right)$, but excluding the transmission losses $(2 T L)$. In the following it is conventionally designated as the "compensated echo level". Sources of its uncertainty include: 
a) the stochastic nature of the physical echo intensity variations. An ensemble average process helps in reducing the variance around the estimated mean, but as the number of available samples is limited, some uncertainty remains in the backscatter estimate;

b) the sonar characteristics including electroacoustic (transducer sensitivity and directivity), and electronic characteristics ( $T x$ power amplification, $R x$ pre-amplification, various gains, filtering, A/D conversion);

c) the environmental conditions (noise level added to the echo level).

The details of MBES-related uncertainty sources in (b) are not always available to end-users and in the absence of this information the sounder must be considered a "black box", without a real estimate of the uncertainty related to its actual transfer function. This uncertainty may be globally determined from experimental data on a controlled target (Lurton and Lamarche 2015), but this can be an expensive, logistically difficult, and time-consuming process.

Additionally, not all MBES systems provide an estimate of $S_{b}$ in the recorded data, but rather only the $D N$ values. Even when $S_{b}$ values are explicitly provided in datagrams, they must still be considered cautiously. Specific gains (either static or time-varying gain TVG) are applied before digitization to keep the signal within the ADC input range; these must be removed in order to retrieve the original physical $S_{b}$ values. Such system-specific processing steps, if not correctly implemented by the manufacturer, may result in large offsets in the reported $S_{b}$. Several studies have highlighted these MBES-design shortcomings (Fonseca et al. 2006; Gavrilov and Parnum 2010; Greenaway and Weber 2010; Hughes Clarke 2012; Brown et al. 2015).

2. The second component $\{2 T L\}$ is the two-way transmission loss between the sonar and the target. It features both the geometrical divergence loss (function of the oblique range) and the absorption loss (depending on both the range and the local absorption coefficient, a function of frequency and water properties). The uncertainty in $T L$ is mainly controlled by both the range estimation accuracy and the knowledge of the seawater characteristics involved in absorption.

3. The third component $\left\{10 \log _{10} A\right\}$ is the insonified footprint area instantaneously active in the backscatter process delimited by the sounder beam pattern and/or the pulse duration. This component also depends on the propagation range and the incident angle of the signal on the seafloor (to be considered in a 3-D geometry) (Fig. 1). 


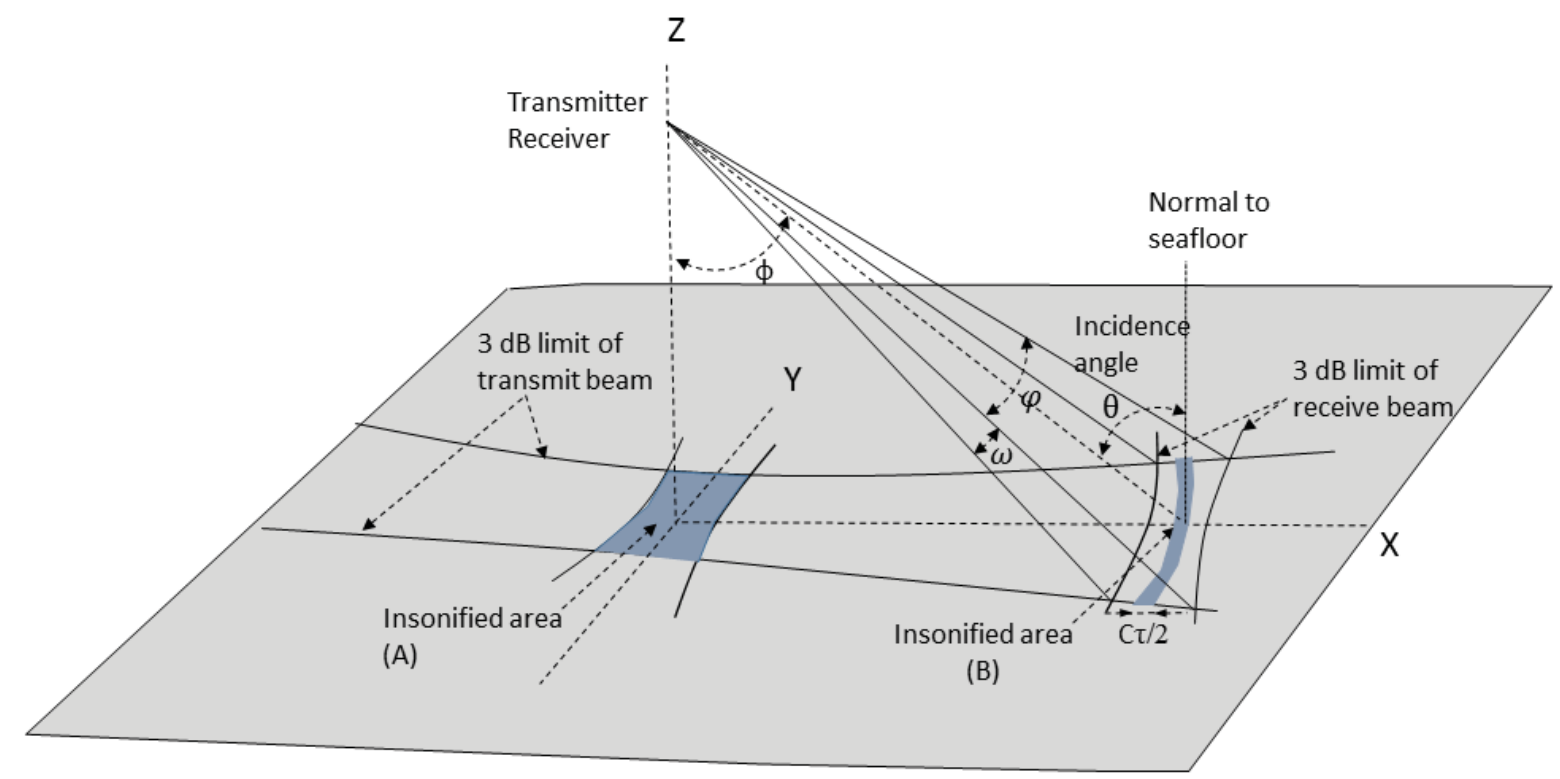

Figure 1: Measurement geometry of MBES and area insonified for near nadir (A) and at oblique angle (B).

Additionally to these three sources of radiometric measurement uncertainty, the incidence angle estimation, upon which $S_{b}$ is dependent, can be another major cause of uncertainty. The $S_{b}$ dependence on seafloor incidence angle and frequency is a fundamental characteristic of seafloor backscatter data. With the MBES frequency fixed (or slightly varying with different $T x$ sectors), the mean seafloor angular response $(A R)$ is characterized by its $S_{b}$ values associated with incidence angles. Given such relationships, many research efforts have used comparisons of measured $A R$ to theoretical models as a basis for seafloor segmentation and characterization (e.g. De Moustier and Alexandrou 1991; Hughes Clarke et al. 1997; Fonseca and Mayer 2007; Rzhanov et al. 2012). The uncertainty of the incidence angle is a function of $T x$ - $R x$ angle estimation accuracy, refraction by the sound-speed profile, and seafloor local slope. The position of the backscatter samples, similar to bathymetric samples, is determined through use of MBES geometry and positioning of the vessel. The Total Horizontal Uncertainty (THU) in the position of soundings, at the 95 percent confidence level, is not expected to exceed 5 meters +5 percent of the depth (IHO 2008). For backscatter samples, the effect of position uncertainty is therefore assumed to be negligible in this paper.

\section{Elementary analysis of major uncertainty components}

As outlined above, the elementary analysis proposed here focuses on the magnitude of the $S_{b}$ uncertainty broken down into the four parameters controlling the $S_{b}(\theta)$ estimate: compensated echo level, seafloor incidence angle, transmission loss, and insonified area. In evaluating the 
sources of uncertainty, two significance thresholds of $1 \mathrm{~dB}$ and $1^{\circ}$ are adopted here for radiometric and geometric uncertainties respectively. These values are selected based on the observation that in order to differentiate confidently between seafloor types, differences in backscatter levels of approximately $1 \mathrm{~dB}$ are needed (Lucieer et al. 2017).

\subsection{Compensated echo level}

\subsubsection{Random fluctuations of the echo level and SNR}

The stochastic nature of the backscatter process results in a randomly-fluctuating sonar echo level (Urick 1983). A simplified but widely used theoretical model assumes backscatter amplitudes to follow a Rayleigh distribution, implying a standard deviation of $5.57 \mathrm{~dB}$ for elementary backscatter samples (Dyer 1970; Jackson and Richardson 2007). Physically interpreted, this model assumes an instantaneous insonified area (signal footprint) wide enough to enclose a large number of simultaneously activated scatterers with statistically independent random phases (Stanic and Kennedy 1992). In order to reduce the resulting uncertainty associated with randomly fluctuating sonar echo levels, the backscatter level can be averaged over an increasing number of signal samples (Peritsky 1973), however at the cost of degraded resolution. For MBES measurements, the number of samples available for averaging depends on depth, system parameters, and angular region of the measurement, and ultimately controls the random uncertainty of the mean backscatter (Jackson and Richardson 2007). A more detailed discussion of the statistical uncertainty of the echo-level can be found in Appendix A.

The echo level measurement uncertainty also depends on the signal-to-noise ratio (SNR). Noise sources in ocean are numerous and highly variable (Urick 1983), including noise caused by seasurface agitation, biology, and bubbles created by the ship motion and/or surface wave action. Also, the sonar performance may be limited by reverberation in the water column due to biological, gaseous or inorganic scatterers. Self-noise caused by the sonar and its carrier platform adds to these environment-related causes. A SNR better than $10 \mathrm{~dB}$ (Lurton and Augustin 2010) can be taken as a reasonable lower limit for acceptable measurements of bathymetry according to today's standards (IHO 2008). A generalized prediction of uncertainty caused by SNR is not suggested here as there are too many causes and individual cases may degrade $S N R$ up to a level such that backscatter measurements are no longer possible. The $S_{b}$ uncertainty due to SNR can be simply modelled as:

$$
\delta S_{b}=10 \log _{10}\left(\frac{S+N}{S}\right)=10 \log _{10}\left(1+10^{-\frac{S N R}{10}}\right)
$$

where $S$ and $N$ are the intensities of the expected signal and the additive noise respectively, defining $S N R=S / N$. Assuming the worst case of a $10 \mathrm{~dB} S N R$, the corresponding uncertainty in backscatter measurements is around $0.4 \mathrm{~dB}$ (increase in the resulting average intensity for \{signal + noise compared to signal alone). Therefore, while SNR can be a major uncertainty source in some individual measurement scenarios, $S N R$ can be practically considered as a minor source of uncertainty for MBES data if currently acceptable quality for bathymetry is achieved. 
Recommendations for improving the MBES data reliability in relation to SNR can be found in Rice et al. (2015).

\subsubsection{Uncertainty of source level and receiver sensitivity}

A detailed characterization of uncertainty in the MBES parameters is still lacking (Lamarche and Lurton 2017). MBES manufacturers have only offered nominal magnitudes of uncertainty related to backscatter measurements. For example, for Kongsberg systems Hammerstad (2000) provided a typical uncertainty of $\pm 1 \mathrm{~dB}$ related to MBES transducer sensitivities but cautioned that this uncertainty might be larger for a specific system. Although several studies have attempted to measure sonar sensitivity in calibration tanks and by field comparisons (Fonseca et al. 2006; Lanzoni and Weber 2011; Rice et al. 2012; Welton 2014), MBES electronics are complex and there are many causes of instrumental uncertainty that users cannot be expected to measure and estimate, let alone keep track of the various engineering parameters needed to confidently estimate these uncertainties. Involvement of MBES manufacturers is therefore critically needed to model the MBES characteristics essential for calibration.

\subsubsection{Relative sonar calibration}

In absence of a readily available calibration documentation, users have to rely on empirical data to derive the calibration offsets. Often, while repeating backscatter measurements over the same seafloor using different settings or with different MBES systems, discrepancies in the observed backscatter values are observed. These differences can then be estimated to adjust backscatter values to match in a relative sense. This empirical method to make backscatter data consistent among different settings or MBES systems is called relative calibration. The adjustment protocols for relative calibration operations and the removal of systematic artifacts have been studied extensively (Hughes Clarke et al. 1996; Hellequin et al. 2003; Augustin and Lurton 2005; Llewellyn 2006; Fonseca et al. 2006, Chu and Hufnagle 2006; Fonseca et al. 2009; Parnum and Gavrilov 2011; Teng 2011; Hughes Clarke 2012; Hiroji 2016). These relative calibration protocols can provide valuable information about the overall health of the MBES including system degradation due to transducer aging or bio-fouling (Lehaitre et al. 2008) and therefore are also being incorporated into sonar acceptance protocols (Beaudoin et al. 2012; Rice and Malik 2015; Hauser et al. 2015). While such relative calibrations provide a means to have the same seafloor appear to have consistent backscatter irrespective of different settings or MBES systems used, it provides no indication of the actual backscatter uncertainty.

\subsubsection{Absolute sonar calibration}

As individual MBES systems may show differences in calibration from system to system, the only alternative to manufacturer-provided information is to subject MBES to empirical checks in a tank or at sea. The aim of this MBES calibration is to estimate the device-related parameters required for $S_{b}$ estimation including: transmit and receive beam patterns, pulse length and the quantitative impact of gain changes applied during the data acquisition. Absolute calibration using reference spheres is a well-accepted method developed for fisheries sonars and proposed 
for application to MBES (Foote et al. 2005, Lanzoni and Weber 2011, Demer et al. 2015): using this method, the combined transmit and receive characteristics of the sonar are measured. The two-way beam pattern thus obtained can be used as a single correction to the measured backscatter. Since accurate placement and controlling motion of a reference sphere inside MBES narrow beam patterns are challenging, a calibration approach using extended targets has also been demonstrated (Heaton et al. 2013). An alternate method to target calibration (either sphere or extended target) is the use of a reference hydrophone (Demer et al. 2015); this method is required if transmitter and receiver characteristics need to be determined separately (Johannesson and Mitson 1983). For practical reasons, the use of hydrophones and transducers in a tank is suitable only for high-frequency portable systems with small arrays. Alternately this method has also been used to measure the beam pattern of a large array by fitting a hydrophone on an ROV (Fusillo et al. 1996), however, this approach is complex and expensive. Finally, using a reference seafloor patch as a benchmark (Eleftherakis et al. 2018; Ladroit et al. 2018) is an attractive option although the seafloor backscatter itself may change depending on a number of factors including temporal changes due to sediment movement and the formation of bedforms and other features that can cause seafloor backscatter to have strong dependence on azimuth (Lurton et al. 2017).

Given that a general model for this class of drifting uncertainty cannot by defined and hence applied to quality control of backscatter data, the reality is that if a reduction in this source of uncertainty is desired, it is currently the user's responsibility to conduct regular calibration operations, either by test tank measurements, surveys on reference seafloor areas, or by comparison with calibrated sonar systems (Lurton and Lamarche 2015).

\subsection{Incidence angle}

The incidence angle considered in seafloor backscatter computations is the angle between the signal arrival direction at the seafloor and the local perpendicular to the interface (considered as locally flat although possibly tilted). The incidence angle uncertainty depends on three components:

A. The angle measured by the sounder at the receiving array $(R x)$, relative to the vertical. This measurement depends both on the intrinsic performance of the sensor array processing and on the platform motion (normally compensated for, with some instrumental uncertainty). The angles associated with the backscatter signal samples are referenced to the arrival angle at the sounding point (bottom detect) of the beam. Hence this instrumental uncertainty is equivalent to the one considered for the bathymetry uncertainty budget (Hare et al. 1995). Considering that most of the bathymetry relative error is given by its angle component (Lurton and Augustin 2010; Hare 2001):

$$
\frac{\delta z}{Z}=\tan \theta \cdot \delta \theta
$$


and using typical magnitudes met for acceptable-quality bathymetry data measured by MBES, one finds an angle error around $0.15^{\circ}$ for limit values of $\delta z / z=1 \%$ and $\theta=75^{\circ}$.

This angular uncertainty is increased by the beam-pointing uncertainty caused by the ship motion, but considering the high accuracy of today's motion sensors (typical uncertainty for roll, pitch and heading accuracy is below $0.1^{\circ}$ ) the quadratically-cumulated angular uncertainty due to both sensor and ship motion can be considered to stay below $0.2^{\circ}$ and hence can be neglected.

B. The effect of refraction due to propagation inside the water column. Uncertainties in the estimated sound speed profile impact the accuracy of compensation for the refraction effect. The sound speed profile has a twofold effect on incidence angle estimation: (1) the beam steering angle at the sonar's head; and (2) refraction in the water column. Angular uncertainty introduced in the computation of beam steering by a sound speed uncertainty $\delta c_{s}$ at the sonar head is given by (Hare et al. 1995):

$$
\delta \emptyset_{s}=\frac{\tan \emptyset_{s}}{c_{s}} \delta c_{s}
$$

where $\emptyset_{s}$ is the beam steering angle from nadir and $c_{S}$ is the sound speed at the sonar head used for beam steering. In most MBES, the sound speed at the sonar head is continuously measured by a dedicated probe, and therefore the sound speed uncertainty is not expected to be more than $\approx 1 \mathrm{~m} / \mathrm{s}$. Considering a pessimistic $\delta c_{S} / c_{s}=0.1 \%$ (i.e. $\delta c_{S}=1.5 \mathrm{~m} / \mathrm{s}$ ), the uncertainty in beam steering will be $\delta \emptyset_{S} \approx 0.2^{\circ}$ at $\emptyset_{S}=75^{\circ}$.

Using the complete sound speed profile to compute an average value $\mathrm{c}_{p}$ the effect of an uncertainty $\delta \mathrm{c}_{p}$ upon the incidence angle $\theta$ (referenced to nadir) can also be estimated as:

$$
\delta \theta_{p}=\frac{\tan \theta}{\mathrm{c}_{p}} \delta \mathrm{c}_{p}
$$

giving the same magnitude of $0.2^{\circ}$ in the pessimistic case of $\delta \mathrm{c}_{p} / c_{p}=0.1 \%$ and $\theta=75^{\circ}$. So considering independent errors on $\mathrm{c}_{s}$ and $\mathrm{c}_{p}$, the incident angle error magnitude should stay within $0.3^{\circ}$.

In summary, the effect of beam steering and refraction on seafloor incidence angle is negligible considering sound speed uncertainties remain smaller than $0.1 \%$.

C. The seafloor local slope. This is best estimated from the Digital Terrain Model (DTM) built from the MBES bathymetry. Three cases can be considered for evaluating the seafloor slope influence on incidence angle uncertainty:

(i) The slope is completely ignored i.e., the seafloor is assumed to be flat and horizontal. The error in the incidence angle will be equal to the slope of the seafloor. This simplification is still commonly applied at basic levels of 
backscatter processing but should be avoided in case of requirements of a good quality backscatter level;

(ii) The seafloor topography is accounted for using a previously-determined DTM. This is normally achievable by most modern seafloor-mapping sonars providing both bathymetry and backscatter data. However, DTM slopes are subject to uncertainties linked to the bathymetry measurement accuracy and to the details of the processing steps applied for their construction;

(iii) Even for seafloor slopes inferred from a DTM, small-scale slopes in the bathymetry may be unresolved and hence affect the estimate of local incidence angle. Little can be derived from MBES bathymetric data about unresolvable small-scale slopes and thus remains an unquantifiable uncertainty source.

In DTM slope calculations, the random vertical uncertainty in the soundings is considered the most critical uncertainty source. Determining the uncertainty in slope estimation, based on resolution, DTM uncertainty, analysis scale and computation algorithm, is an active area of research in terrain analysis and modeling. Dolan and Lucieer (2014) and Zhu et al. (2014) have shown uncertainties in slopes to reach up to $5^{\circ}$ $6^{\circ}$ when using a MBES-derived DTM. Furthermore, assumptions about the macro-relief of the surveyed seafloor at the spatial resolution of the backscatter samples are needed for an a-priori estimate of slope uncertainty; for most MBES this cannot be assessed by using only the bathymetry available from the MBES.

Although uncertainty due to the above individual sources (beam pointing angle, refraction and seafloor slope) cannot be differentiated from the beam pointing angle measurement itself, the incidence angle uncertainty affects the $S_{b}$ measurement in two ways:

- the angle at which measured $S_{b}$ is reported;

- the footprint area computation that impacts the echo level computation term $\left(\left\{10 \log _{10} A\right\}\right.$ in [Eq. 6]) as it is related to the incidence angle.

The magnitude of the impact of a wrong angle estimate on the resulting angular backscatter curve can be demonstrated using the derivative (vs. angle) of a canonical angular backscatter model. Using for instance the GSAB model (Lamarche et al. 2011) in its simplest form (a Gaussian law for specular regime and Lambert's law at oblique incidences) leads to the results presented in Fig. 2. The expressions for $\sigma_{b}$, its differential $\frac{\partial \sigma_{b}}{\partial \theta}$ and the corresponding uncertainty $\delta S_{b}$ in $\mathrm{dB}$ are given by: 


$$
\begin{gathered}
\sigma_{b}=A \exp \left(-\frac{\theta^{2}}{2 B^{2}}\right)+C \cos ^{D} \theta \\
\frac{\partial \sigma_{b}}{\partial \theta}=-\frac{A \theta}{B^{2}} \exp \left(-\frac{\theta^{2}}{2 B^{2}}\right)-C D \cos ^{(D-1)} \theta \sin \theta \\
\delta S_{b}=\frac{10}{\ln 10} \frac{\partial \sigma_{b}}{\partial \theta} \frac{\delta \theta}{\sigma_{b}}
\end{gathered}
$$

364

where $A$ is the specular maximum amplitude, $B$ is the facet slope standard deviation, $C$ quantifies the average backscatter level at oblique incidence and $D$ is the backscatter angular decrement.
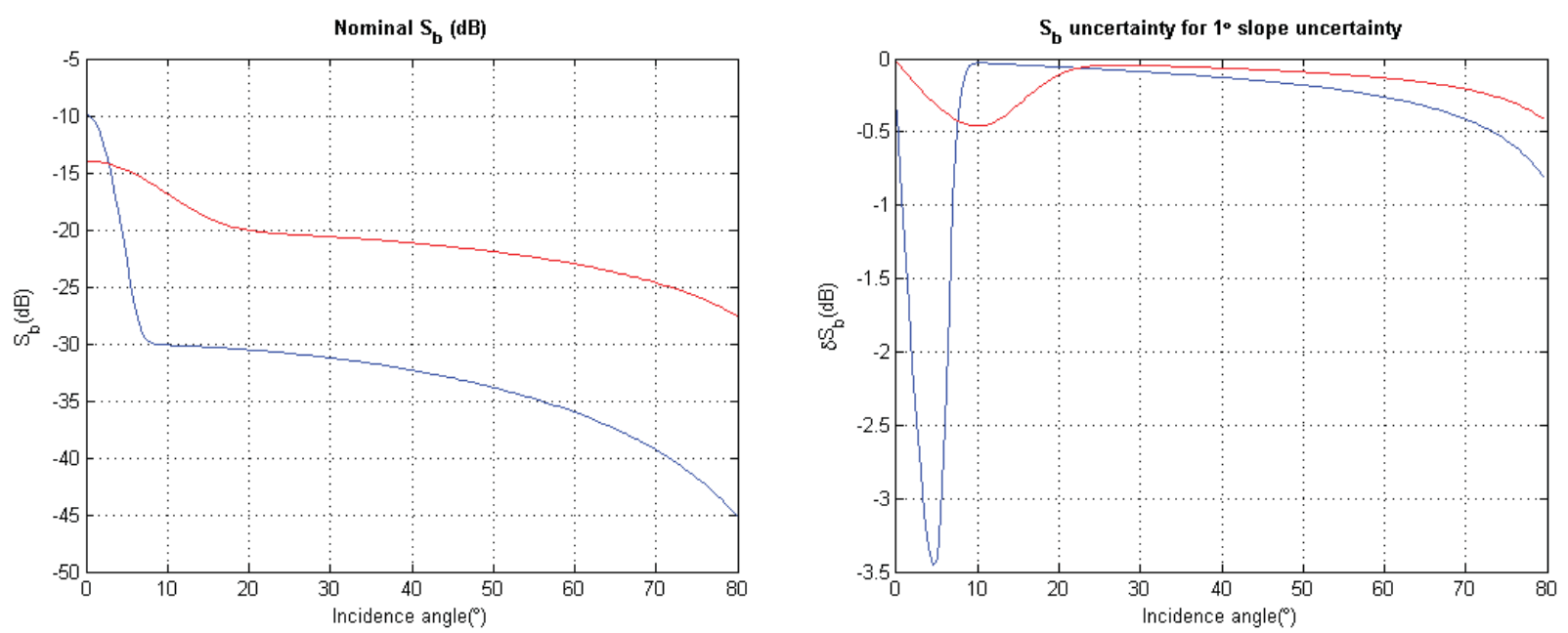

Figure 2: Effect of incident angle uncertainty on backscatter. Two nominal angular backscatter curves representing different seafloor types (blue and red, left), and the effect of a $1^{\circ}$ slope angle uncertainty on the backscatter values (corresponding colors, right). The impact is maximal in the specular region, where the cut-off effect corresponds to the strongest angular variations $\left(0^{\circ}\right.$ to $10^{\circ}$ or $0^{\circ}$ to $20^{\circ}$ according to the case); it is negligible in the "plateau" angle sector $\left(10^{\circ}-20^{\circ}\right.$ to $\left.50^{\circ}-60^{\circ}\right)$ and increases at high incidence angles.

The two cases illustrated in Fig. 2 are typical angular backscatter curves for a soft-sediment (in blue, high narrow specular backscatter, decreasing in oblique region with $\cos ^{2} \theta$ ) and a coarse sediment (in red, low and wide specular backscatter, decreasing in oblique region with $\cos \theta$ ). For most seafloors the oblique-regime average angle dependence lies between the $\cos \theta$ and $\cos ^{2} \theta$ curves shown here. The model input parameters $(A, B, C, D)$ are respectively $\left(0.1 ; 2^{\circ}\right.$; $0.001 ; 2)$ and $\left(0.03 ; 7^{\circ} ; 0.01 ; 1\right)$. As expected, the impact of incidence angle uncertainty is maximal for the specular regime; in this region its magnitude depends on the specular lobe slope and may reach several $\mathrm{dB}$ for a $1^{\circ}$ angular change. On the other hand, the sensitivity to incidence angle uncertainty becomes negligible on the "plateau" regime $\left(10^{\circ}-20^{\circ}\right.$ to $\left.50^{\circ}-60^{\circ}\right)$ where the $S_{b}$ variation with angle is small. At higher angles ( $>70^{\circ}$ in this example) the angle dependence increases again. In summary the angular dependence at steep angles varies strongly with the specular lobe, while the oblique regime shows a much more stable behavior regardless of the 
seafloor type. This stability with angle is one of the major advantages of using the plateau region of incidence for backscatter measurements by MBES and should be preferentially used while comparing one backscatter survey to the other. This approach is also taken by space-borne radars which measure reflectivity only using a subset of the oblique regime (Long and Skouson 1996; Prigent et al. 2015).

\subsection{Transmission loss}

The transmission loss includes two effects (Urick 1983): geometrical divergence (energy spreading along propagation path) and absorption (due to physicochemical properties of seawater). The one-way transmission loss (TL) referenced to a $1 \mathrm{~m}$ conventional range is classically written:

$$
T L=20 \log _{10} R+\alpha R
$$

where $R$ is the range (in $\mathrm{m}$ ), $20 \log _{10} R$ is the spherical spreading $\operatorname{loss}\left(20 \log _{10} R\right.$ is used instead of the correct form $20 \log _{10}\left(R / R_{0}\right)$ for notation simplicity, where $R_{0}=1 \mathrm{~m}$ is the reference unit distance), and $\alpha$ is the absorption coefficient. Hence the uncertainty in $T L$ will include the combined effects of uncertainties in the measured range (present in both terms) and the absorption coefficient.

\subsubsection{Range impact upon spreading loss}

The two-way spreading loss considered here is given by $2 T L_{S}=40 \log _{10} R$. The geometrical range $R$ is determined by measurement of the time-of-flight $t$ and the average sound speed $\bar{c}$ between source and target, through the elementary relation

$$
R=\frac{\bar{c} t}{2}
$$

Therefore, the range uncertainty is due to both uncertainties in time measurement and average sound speed $(\delta \bar{c})$; its relative value is the quadratic summation of the values for time and sound speed, assumed to be independent:

$$
R=\frac{\bar{c} t}{2} \Rightarrow \frac{\delta R}{R}=\sqrt{\left(\frac{\delta t}{t}\right)^{2}+\left(\frac{\delta \bar{c}}{\bar{c}}\right)^{2}} .
$$

The minimum travel-time uncertainty $\delta t$ is bounded by the sampling step of the digitized time signal, normally smaller than half the pulse duration. For instance, for a high-frequency MBES transmitting $0.2 \mathrm{~ms}$ pulses in a $50 \mathrm{~m}$ water depth (z), the range uncertainty is bounded by $\delta t=T / 2=0.1 \mathrm{~ms}$, compared to a minimum two-way travel time of $2 z / c=66 \mathrm{~ms}$; so the relative error in this case is $\delta t / t \approx 0.15 \%$. Note that an approximate linear scaling exists for the various categories of MBES for pulse duration vs. depth range; e.g. a low-frequency MBES typically 
414

415

416

417

418

419

420

421

422

transmits $20 \mathrm{~ms}$ pulses in a $5000 \mathrm{~m}$ water depth, hence the same magnitude for $\delta t / t$ is expected for different operational depths.

The $\delta \bar{c}$ magnitude arises from the sound speed measurement uncertainty, which is expected to be better than $0.5 \mathrm{~m} / \mathrm{s}$ (e.g. Sea-Bird Electronics Inc. 2010), as well as due to spatial and temporal water column variability (Beaudoin et al. 2009). The relative uncertainty $\delta \bar{c} / \bar{c}$ integrated over the water depth is not expected to be more than $0.1 \%(\delta \bar{c} \sim 1.5 \mathrm{~m} / \mathrm{s})$.

With these magnitudes of $\delta \bar{c} / \bar{c}=0.1 \%$ and $\delta t / t=0.1 \%$ the range-relative uncertainty expressed in [Eq. 15] is about $\delta R / R=0.18 \% \approx 0.2 \%$.

Finally, the associated spreading loss uncertainty is given by:

$$
\delta_{R}\left(2 T L_{S}\right)=40 \log _{10}\left(1+\frac{\delta R}{R}\right) \approx 40 \log _{10}(1.002) \approx 0.035 \mathrm{~dB} .
$$

This result is independent of the range and is valid for all MBES categories and propagation ranges. Moreover, the range term featured in the transmission loss is partly compensated by its role in the footprint area $A$ expression, proportional either to $R$ or to $R^{2}$. Thus, the actual final dependence of the $S_{b}$ value upon range will be $20 \log _{10} R$ or $30 \log _{10} R$, instead of $40 \log _{10} R$ and the maximum uncertainty in spreading loss, corresponding to [Eq. 16] should be either 0.018 $\mathrm{dB}$ (for $20 \log _{10} R$ ) or $0.027 \mathrm{~dB}$ (for $30 \log _{10} R$ ). To conclude, the $S_{b}$ uncertainty caused by the range uncertainty on the geometrical divergence component of the propagation loss is less than $0.03 \mathrm{~dB}$ and can be considered negligible.

\subsubsection{Range impact upon absorption loss}

The absorption loss is given by $2 T L_{a b s}=2 \alpha R$. Hence its range-dependent uncertainty for a $\delta R$ range variation is:

$$
\delta_{R}\left(2 T L_{a b s}\right)=2 \alpha \delta R=2 \alpha R \frac{\delta R}{R}
$$

with the right-hand term containing the product of the absorption loss and the relative uncertainty in range. The relative uncertainty in range is typically $0.2 \%$ or less; hence for a numerical estimation of [Eq. 17] the magnitude of $2 T L_{a b s}=2 \alpha R$ has to be specified. Four cases are considered here for different frequencies and maximum oblique ranges typical of various MBES categories (deep, medium, shallow, very shallow) (Tab. 1). The results in Table 1 show that the $S_{b}$ uncertainty due to range in the absorption effect can reach a magnitude of $0.08 \mathrm{~dB}$ in the worst cases (extreme oblique range, intermediate frequencies $30-100 \mathrm{kHz}$ with a $0.1 \%$ uncertainty in range) - and hence is a negligible effect. 
Table 1: Uncertainty [Eq. 17] in transmission loss due to range uncertainty for four typical categories of multibeam echosounders.

\begin{tabular}{|l|l|l|l|l|}
\hline MBES category & Deep & Medium & Shallow & Very Shallow \\
\hline Frequency $(\mathrm{kHz})$ & 12 & 30 & 100 & 300 \\
\hline Approximate absorption coeff. $\alpha(\mathrm{dB} / \mathrm{km})$ & 1.2 & 6.7 & 33.2 & 72.5 \\
\hline Max depth z $(\mathrm{m})$ & 5000 & 2000 & 300 & 50 \\
\hline Max oblique range $(\mathrm{m}) R_{\max }=\mathrm{z} / \cos 75^{\circ} \approx 4 \mathrm{z}$ & 20000 & 8000 & 1200 & 200 \\
\hline Max absorption loss $(\mathrm{dB}) 2 \alpha R_{\max }$ & 48.0 & 107.2 & 79.7 & 29.0 \\
\hline Uncertainty [Eq. 17] $(\mathbf{d B})$ for $\delta R / R=0.1 \%$ & $\mathbf{0 . 0 4}$ & $\mathbf{0 . 1}$ & $\mathbf{0 . 0 8}$ & $\mathbf{0 . 0 3}$ \\
\hline
\end{tabular}

\subsubsection{Absorption coefficient}

The $2 T L_{a b s}$ uncertainty due to an absorption coefficient uncertainty $\delta \alpha$ is given by:

$$
\delta_{\alpha}\left(2 T L_{a b s}\right)=2 R \delta \alpha=2 \alpha R \frac{\delta \alpha}{\alpha}
$$

449

450

451

452

453

454

455

456

457

458

459

460

461

462

463

464

465

where the relative uncertainty in absorption coefficient $\delta \alpha / \alpha$ has been made explicit. The absorption effect is a combination of the intrinsic absorption coefficient of the seawater (depending both on the absorption model reliability and on the accuracy of the measurements of estimates of local water properties) and the possible additional absorption caused by events in the water column such as bubble clouds (close to the surface or the ship's hull) or suspended sediments (close to the seafloor). The latter effect is more prone to impact high-frequency systems in shallow waters, while surface bubbles can impact systems in any water depth. Unfortunately, it is very difficult to assume a priori realistic magnitudes for such causes of uncertainty. The underlying physical phenomena controlling the intrinsic absorption coefficient of seawater are well understood and several models exist, based on fitting datasets of empirical measurements. Although more recent models have been proposed (Ainslie and McColm 1998), the model by Francois and Garrison (1982) is the most commonly used today, with a reported accuracy of $5 \%$. To reduce this uncertainty, more direct observations of absorption coefficients are needed (Doonan et al. 2003). A rough estimate of uncertainty in transmission loss is proposed in Table 2 for an assumed $\delta \alpha / \alpha$ ranging from $1 \%$ to $10 \%$.

Table 2: Uncertainty in transmission loss due to absorption coefficient uncertainties (1\% and 10\%) for four typically-used frequencies of MBES.

\begin{tabular}{|l|l|l|l|l|}
\hline MBES category & Deep & Medium & Shallow & Very Shallow \\
\hline Frequency $(\mathrm{kHz})$ & 12 & 30 & 100 & 300 \\
\hline Absorption coeff. $\alpha(\mathrm{dB} / \mathrm{km})$ & 1.2 & 6.7 & 33.2 & 72.5 \\
\hline Max depth $\mathrm{z}(\mathrm{m})$ & 5000 & 2000 & 300 & 50 \\
\hline Max oblique range $(\mathrm{m}) R_{\max }=\mathrm{z} / \cos 75^{\circ} \approx 4 \mathrm{z}$ & 20000 & 8000 & 1200 & 200 \\
\hline Max absorption loss $(\mathrm{dB}) 2 \alpha R_{\max }$ & 48.0 & 107.2 & 79.7 & 29.0 \\
\hline Max. $2 \mathbf{2 L}_{\text {abs }}$ uncertainty $(\mathbf{d B})$ for $\delta \alpha / \alpha=1 \%$ & $\mathbf{0 . 4 8}$ & $\mathbf{1 . 0}$ & $\mathbf{0 . 8}$ & $\mathbf{0 . 3}$ \\
\hline Max. $2 \mathbf{2 L}_{\text {abs }}$ uncertainty $(\mathbf{d B})$ for $\delta \alpha / \alpha=10 \%$ & $\mathbf{4 . 8}$ & $\mathbf{1 0}$ & $\mathbf{8}$ & $\mathbf{3}$ \\
\hline
\end{tabular}


Therefore in the most probable practical cases of a few percent of relative uncertainty $\delta \alpha / \alpha$ considered at the maximum oblique range of the sounder, the absorption uncertainty may reach several $\mathrm{dB}$ (up to $10 \mathrm{~dB}$ in the worst case of Tab.2). These estimates can be refined through a computation as a function of incident angle, for various frequencies and water depths; Fig. 3 presents such results for a pessimistic $\delta \alpha / \alpha=10 \%$. This figure illustrates that uncertainty in seawater absorption coefficient, even at lower levels, can be expected to be a major factor in the final $S_{b}$ estimation accuracy, especially in the case of medium frequencies (30 and $100 \mathrm{kHz}$ ).

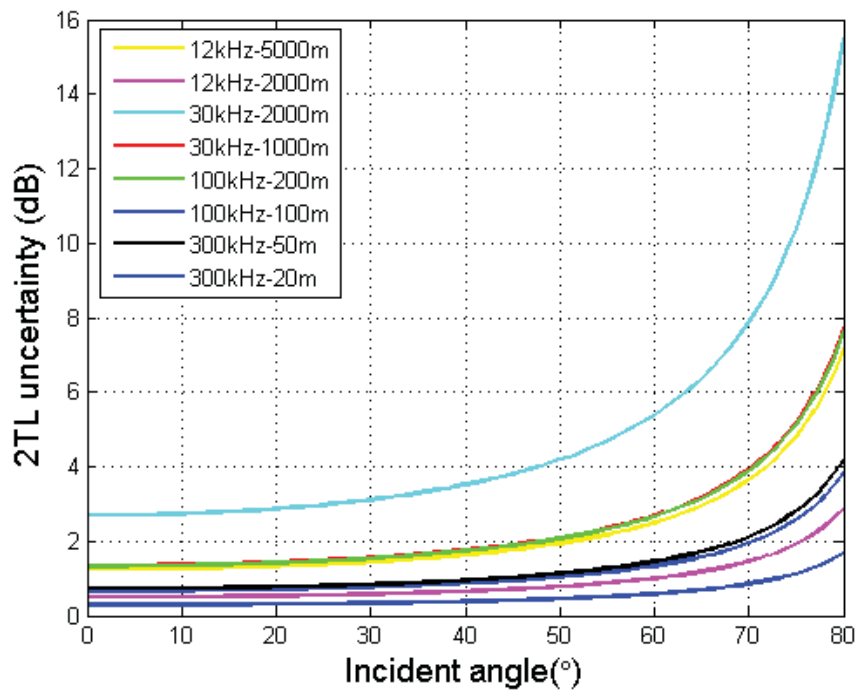

Figure 3: Expected uncertainty (on $2 T L$, or on $S_{b}$ ) resulting from a $10 \%$ uncertainty in absorption coefficient, based on the same parameters (frequency - water depth) as in Table 2.

In summary, the main factor to consider for the backscatter uncertainties due to transmission loss is the absorption coefficient which can result in uncertainties in backscatter estimates of several dB (Tab. 2, Fig. 3). The effects caused by the propagation range uncertainty are negligible in comparison.

\subsection{Insonified area}

Knowledge of the insonified area $A$ is required to determine the backscatter strength defined per unit area $\left(10 \log _{10} A\right.$ in [Eq. 6]). In the classical Mill's cross configuration for MBES arrays, the insonified area extent in the along-track direction is defined by the $T x$ sector beamwidth (Lurton 2010). For the oblique incidence region, the across-track extent of the insonified area is bounded by the pulse length projection over the seafloor, while in the normal incidence region, it is bounded by the receiver beamwidth (Fig. 1). The detailed accurate computation of the insonified area is complicated if both the full $T x$ and $R x$ beam patterns are considered, however, approximate formulas are commonly used. At oblique incidence (short-pulse regime, see Lurton 2010) the insonified area can be approximated as: 


$$
A \approx \varphi R \frac{c T}{2 \sin \theta \cos \gamma}
$$

and around normal incidence (long-pulse regime) as:

$$
A \approx \varphi \omega R^{2} \frac{1}{\cos \theta \cos \gamma}
$$

491

492

493

494

495

496

497

498

499

500

501

502

503

504

505

506

507

508

509

510

511

512

with $R$ the range; $\varphi$ and $\omega$ the along-track and across-track two way equivalent apertures respectively (Fig. 1); $T$ the pulse length; $c$ the local sound speed; $\theta$ the across-track incidence angle; and $\gamma$ the along-track slope. The pulse length $T$ considered here is either the length of the physically transmitted pulse in case of continuous waves (CW) or the compressed pulse length after matched filtering in the case of frequency modulated (FM) transmitted signals (Lurton, 2010).

These approximations [Eq. 19, Eq. 20] may lead to biases in the backscattering strength estimates. For narrow beams, this bias can practically be ignored (Hellequin et al. 2003). However, for wide beams, the bias can be significant, as shown for radar (Kim et al. 1982; Ulaby et al. 1983; Wang and Gogineni 1991) and sonar backscatter measurements (Matsumoto et al. 1993). MBES beamwidths are today usually less than $2^{\circ}$ so only a minimal effect on the insonified area is expected. Using a point-scatterer model (Ladroit et al. 2012) for a shallowwater MBES (0.15 ms pulse length, $1.5^{\circ}$ along- and across-track beamwidths), a numerical simulation is presented here (Fig. 4) to illustrate the possible bias caused by the approximated formulae used for the insonified area. The area estimated using the simplified equations [Eq. 19, Eq. 20] matches fairly well with the simulated area defined by the idealized beam-pattern, for a range of depths (Fig. 4 shows an example in $50 \mathrm{~m}$ depth) except for a narrow intermediate angular range at the transition between the near-nadir and the oblique-angle regimes where the computed and simulated areas differ more significantly (up to $\sim 0.5 \mathrm{~dB}$ in this example). Thus, the approximations used in footprint area computations can be applied to MBES data without causing significant uncertainty beyond the near-nadir region. The contribution of other terms in [Eq. 19, Eq. 20] in the insonified area estimation are discussed below. 

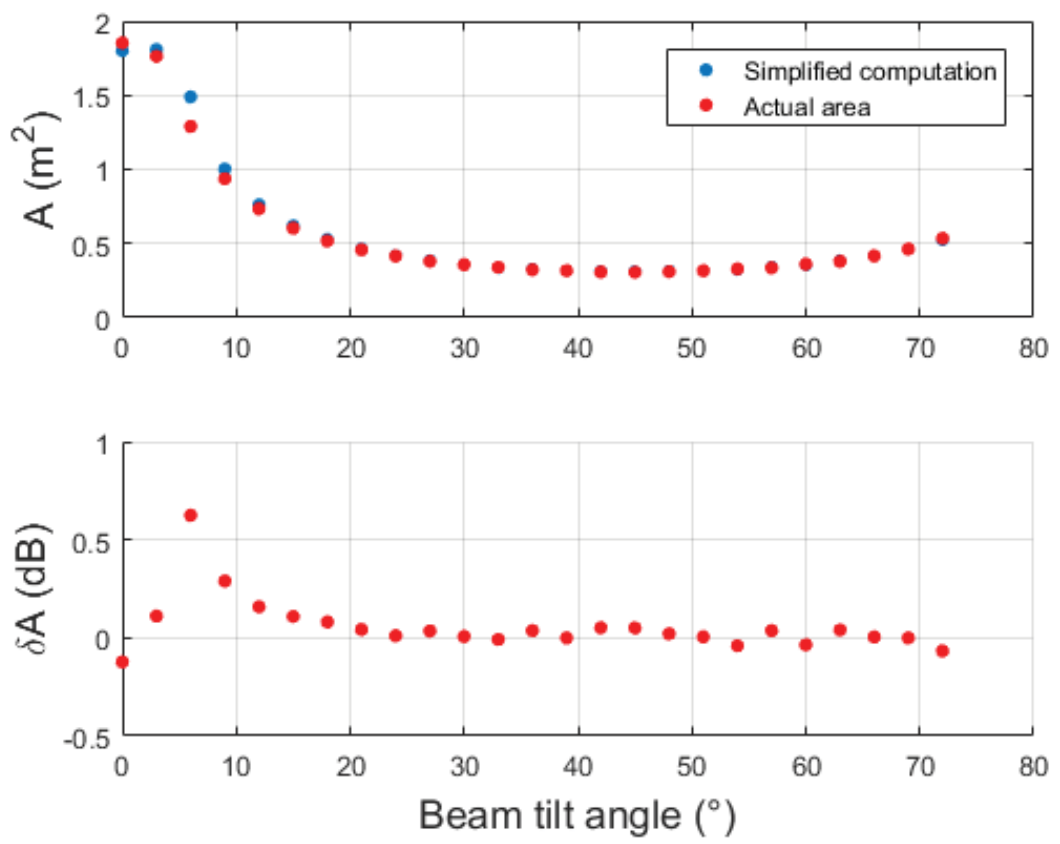

Figure 4: Example of comparison of insonified area estimates based on simplified computation [Eq. 19, Eq. 20] and actual area obtained by numerical simulation. At $\sim 6^{\circ}$, the simplified formula shifts from insonification limited by beam aperture to insonification limited by pulse length, resulting in a slight mismatch with the simulation results. Depth $50 \mathrm{~m}$; pulse duration $0.15 \mathrm{~ms}$; beamwidth $1.5^{\circ}$.

\subsubsection{Range dependence}

The impact of range uncertainty on footprint area is not considered here. It was considered above in the divergence transmission loss analysis and shown to be a parameter of secondary importance.

\subsubsection{Sounder parameters}

The sonar system parameters considered here are the beam apertures ( $\varphi$ and $\omega)$ and the pulse length $T$. Uncertainties in these terms can be caused either by shortcomings in the documentation provided by the manufacturer or by unwanted modifications in the MBES characteristics, for example failure of sonar array elements or inappropriate motion compensation (Gallaudet 2001; Hiroji 2016). In all cases, these uncertainties:

- act as stable biases on the measured/computed backscatter values and can be corrected a posteriori provided that their magnitude is identified;

- should not exceed a few percent, whatever their cause.

Table 3 gives the $S_{b}$ uncertainties (in $\mathrm{dB}$ ) associated with uncertainty of $1 \%$ to $20 \%$ for the input parameters of footprint $A$ (with the $10 \log _{10}$ dependence involved in [Eq. 6]). It is expected that the impact of these uncertainties in the footprint extent would remain small (although not 
negligible, especially if accumulated), considering that the relative uncertainty on the sounder's parameters (beam patterns, pulse length) are likely to stay within few percent.

Table 3: $S_{b}$ uncertainty caused by a relative uncertainty in individual components of insonified area $A$ (beamwidths or pulse length), from $1 \%$ to $20 \%$, expressed in $\mathrm{dB}$ (according to the $10 \log _{10} A$ dependence in [Eq. 6]).

\begin{tabular}{|l|l|l|l|l|l|}
\hline Relative uncertainty (\%) & 1 & 2 & 3 & 10 & 20 \\
\hline Uncertainty in dB & $\mathbf{0 . 0 4}$ & $\mathbf{0 . 0 9}$ & $\mathbf{0 . 2 1}$ & $\mathbf{0 . 4 1}$ & $\mathbf{0 . 7 9}$ \\
\hline
\end{tabular}

\subsubsection{Across-track angle}

Consider here first the angles in the across-track vertical plane (containing the formed beams). The sources of angle errors are presented in §3.2. If the across-track slope of the seafloor is taken into account when computing the incidence angle $\theta$, an uncertainty $\delta \theta$ causes an uncertainty of $A$ given by (for the short-pulse regime [Eq. 19]):

$$
A \propto \frac{1}{\sin \theta} \Rightarrow \frac{\delta A}{A}=\frac{\delta \theta}{\tan \theta} .
$$

So the $S_{b}$ uncertainty caused by angle variations in footprint area is given by:

$$
\delta_{A, \theta} S_{b}=10 \log _{10}\left(1+\frac{\delta A}{A}\right)=10 \log _{10}\left(1+\frac{\delta \theta}{\tan \theta}\right)
$$

Note that normal incidence $(\theta \rightarrow 0)$ is not considered here; the angle dependence [Eq. 18] on $1 / \sin \theta$ is not valid in this regime and must be replaced by the long-pulse regime expression [Eq. 20]:

$$
\begin{gathered}
A \propto \frac{1}{\cos \theta} \Rightarrow \frac{\delta A}{A}=-\tan \theta \delta \theta \\
\delta_{A, \theta} S_{b}=10 \log _{10}\left(1+\frac{\delta A}{A}\right)=10 \log _{10}(1-\tan \theta \delta \theta) .
\end{gathered}
$$

Fig. 5 shows the $S_{b}$ uncertainty considering an uncertainty in the across-track incident angle $(\theta)$ from $-3^{\circ}$ to $3^{\circ}$, for the long- $\left(0^{\circ}\right.$ to $40^{\circ}$ incidence) and short-pulse $\left(15^{\circ}\right.$ to $80^{\circ}$ incidence $)$ cases. The same slope shows reverse effects on the insonified area uncertainty using short- or longpulse regimes, thus giving rise to a step change at the incidence angle where the insonified area shifts from the beam limited (long-pulse) to pulse limited (short-pulse) regime. Overall, the $S_{b}$ uncertainty remains below $0.8 \mathrm{~dB}$ for slope-caused angle uncertainties reaching about $\pm 3^{\circ}$. 


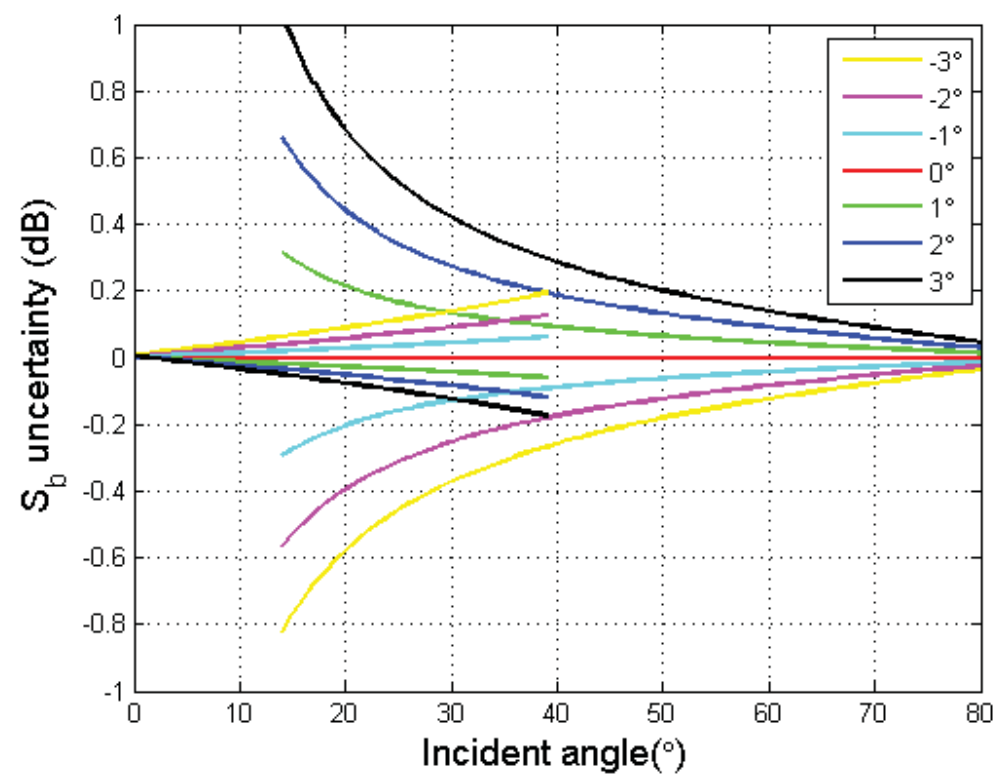

Figure 5: Uncertainty in backscatter strength $\left(S_{b}\right.$ in $\left.\mathrm{dB}\right)$ caused by variations in footprint area due to acrosstrack incident angle uncertainty ranging from $-3^{\circ}$ to $3^{\circ}$ for the long-pulse $\left(0^{\circ}\right.$ to $\left.40^{\circ}\right)$ and the short-pulse cases $\left(15^{\circ}\right.$ to $\left.80^{\circ}\right)$.

If no compensation is applied for the seafloor topography (assumed to be flat and horizontal), then the uncertainty of the footprint area estimate is the difference between the angular dependences $A \propto 1 / \sin \vartheta$ (where $\vartheta$ is the incidence angle for an assumed flat topography) and $A \propto 1 / \sin (\vartheta-\beta)$ (accounting for actual terrain slope $\beta$ ). Hence the uncertainty for the shortpulse regime is expressed in $\mathrm{dB}$ as:

$$
\delta_{A, \beta} S_{b}=10 \log _{10}|\sin \vartheta / \sin (\vartheta-\beta)|
$$

Similarly for the long-pulse regime:

$$
\delta_{A, \beta} S_{b}=10 \log _{10}|\cos \vartheta / \cos (\vartheta-\beta)| \cdot
$$

The resulting $S_{b}$ uncertainty is plotted in Fig. 6 as a function of incidence angle $\left(0^{\circ}\right.$ to $\left.80^{\circ}\right)$ when the seafloor slope $\beta$ (between $-15^{\circ}$ and $+15^{\circ}$ ) is not accounted for, for the long- $\left(0^{\circ}\right.$ to $40^{\circ}$ incidence) and short-pulse ( $15^{\circ}$ to $80^{\circ}$ incidence) regimes. For the long-pulse case, the uncertainty is on the order of $1 \mathrm{~dB}$ for steeper slopes $\left(15^{\circ}\right)$, however, for the short-pulse region the uncertainty in the seafloor for slopes facing towards the MBES causes large uncertainty in $S_{b}$ (e.g., $>3 \mathrm{~dB}$ for $\vartheta=15^{\circ}$ at $\theta<30^{\circ}$ ). Figs. 5 and 6 indicate that the impact of across-track seafloor slope uncertainty is significant and most severe at mid-range incidence angles $\left(20^{\circ}-50^{\circ}\right)$. 


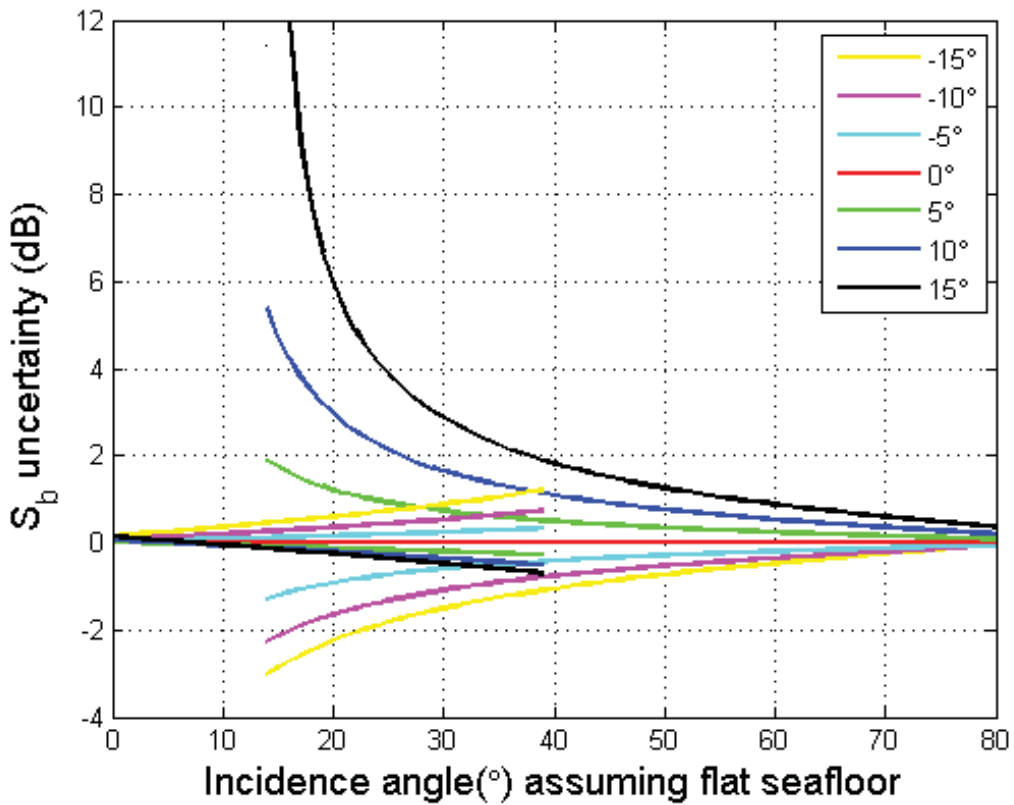

Figure 6: Uncertainty in backscatter strength $\left(S_{b}\right.$ in $\left.\mathrm{dB}\right)$ if the seafloor across-track slope is not considered for area insonified computation. Unaccounted seafloor slopes from $-15^{\circ}$ to $15^{\circ}$ are considered for the longpulse $\left(0^{\circ}\right.$ to $\left.40^{\circ}\right)$ and short-pulse cases $\left(15^{\circ}\right.$ to $\left.80^{\circ}\right)$.

\subsubsection{Along-track angle}

An uncertainty $\delta \gamma$ in the along-track incidence angle $\gamma$ causes an uncertainty in the insonified area $A$ given by [Eq. 19, 20]:

$$
A \propto \frac{1}{\cos \gamma} \Rightarrow \frac{\delta A}{A}=\tan \gamma \delta \gamma
$$

The uncertainty in $S_{b}$ can then be estimated as:

$$
\delta_{A, \gamma} S_{b}=10 \log _{10}\left(1+\frac{\delta A}{A}\right)=10 \log _{10}(1+\tan \gamma \delta \gamma)
$$

For $\delta \gamma$ ranging from $-3^{\circ}$ to $3^{\circ}$ Fig. 7 shows that the $S_{b}$ uncertainty is insignificant for small uncertainties in the incidence angle $\left(1\right.$ or $\left.2^{\circ}\right)$ and/or terrains with smooth topography (along-track slope angles up to $10^{\circ}$ to $15^{\circ}$ ); even for steep areas with higher uncertainties in the topography, the $S_{b}$ uncertainty remains within a few tenths of a dB. 


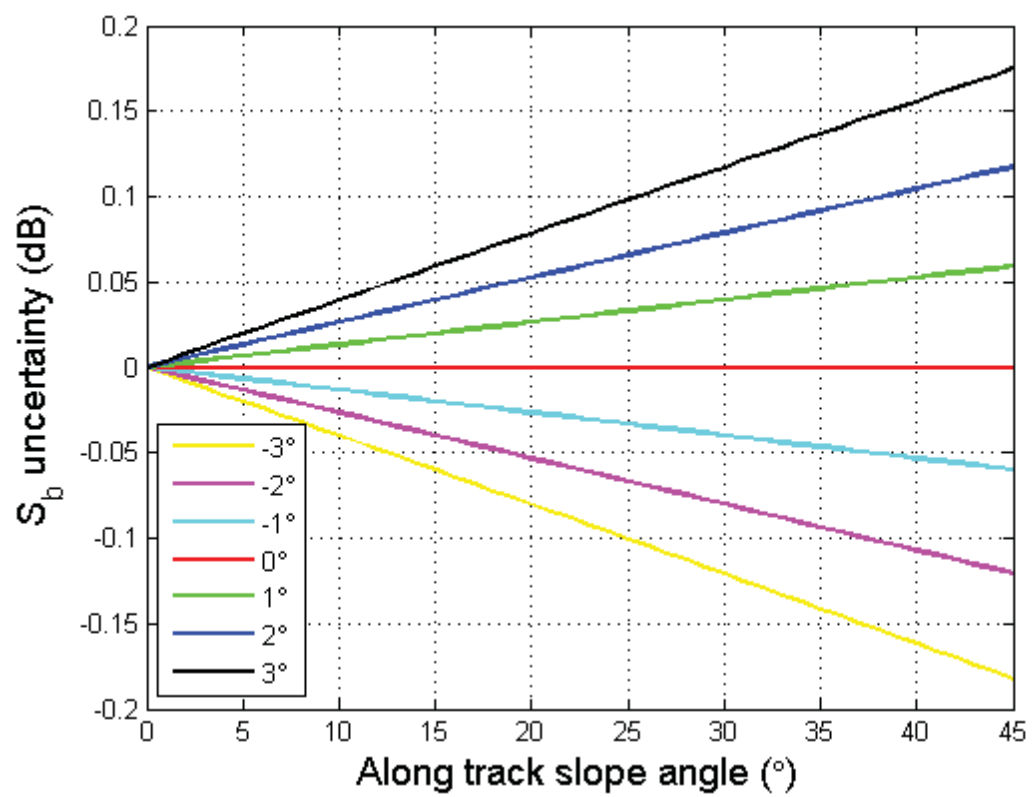

Along track slope angle $\left(^{\circ}\right)$

Figure 7: Uncertainty in $S_{b}$ estimation due to uncertainty in along-track slope.

587 If the along-track slope angle effect is not accounted for (as is often the case), the uncertainty is then directly given by the $1 / \cos \gamma$ term (Fig. 8), where $\gamma$ represents the slope angle. Here again, the $S_{b}$ uncertainty may be negligible for smooth terrains $(<0.1 \mathrm{~dB}$ for incidence angles up to $15^{\circ}$ ) but increases significantly for steeper slopes $\left(>0.5 \mathrm{~dB}\right.$ for slopes $30^{\circ}$ to $\left.45^{\circ}\right)$. Note these results for along-track angles are valid for short- and long-pulse regimes, since both regimes have the same dependence on $1 / \cos \gamma$ (see [Eq. 19, Eq. 20]). 


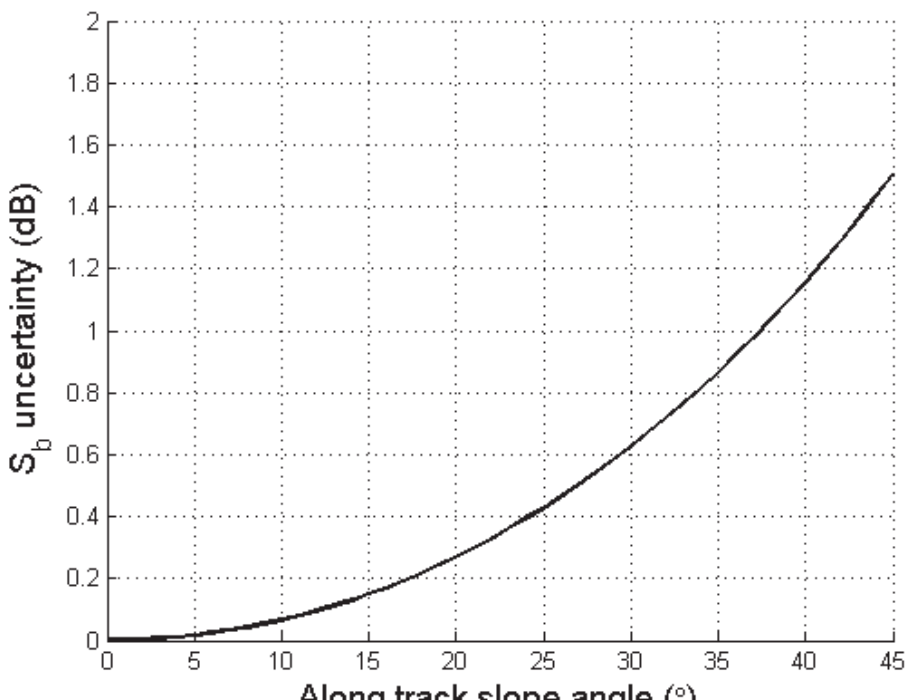

595

596

597

598

599

600

601

602

603

604

605

606

607

608

609

610

611

612

613

614

615

616

617

618

619

Figure 8: Uncertainty in $S_{b}$ estimation if the along-track slope $\left(0^{\circ}\right.$ to $\left.45^{\circ}\right)$ is ignored.

In summary, for the compensation of the insonified area, the impact of inaccuracies in the sounder characteristics remains limited and can reasonably be kept small or negligible. The $S_{b}$ dependence on incidence angle has a far more significant impact, potentially reaching several $\mathrm{dB}$, depending on the beam angle and local seafloor slope. While computing the insonified area, the across-track slope angle plays the major role, while the along-track angle impact remains limited. Completely ignoring the seafloor slope (both across- and along-track) when estimating the footprint extent, logically leads to the largest uncertainties. Fortunately, commercially available backscatter processing software tools have started to address such compensations (e.g., QPS 2014). However, even when accounting for the local slopes, uncertainties of a few degrees may remain and the relations provided above can be used to assess their uncertainty contributions.

\subsection{Summary of the major uncertainty components}

Based on the elementary analysis presented above, the impacts of the main sources of backscatter uncertainty are summarized in Table 4. Each of the causes of $S_{b}$ uncertainty is broken down into "random" or "bias" components. "Random" uncertainties are caused by noise or intrinsic fluctuations (e.g., echo signal instabilities, or small-scale uncertainties in the bathymetry) and can be mitigated through a posteriori statistical processing. "Bias" or systematic uncertainties may be caused by variations in the MBES characteristics, by unaccounted changes in environmental conditions, or by insufficiencies in the processing procedures; they may systematically vary as a function of depth, seafloor slope and ship's motion. They can (up to some point) be corrected a posteriori, although this implies complementary operations that may prove difficult (e.g., sonar calibration, re-computation of the DTM, improved information about the water column). The bias corrections, once applied, still 
have some residual uncertainty that must then be included in the uncertainty budget. The following scale is proposed to classify the magnitude of the uncertainty:

- Negligible $(N): 0.01$ to $0.1 \mathrm{~dB}$

- Small (S): 0.1 to $1 \mathrm{~dB}$

- Moderate $(M): 1$ to $3 \mathrm{~dB}$

- $\operatorname{High}(H): 3$ to $6 \mathrm{~dB}$

- Prohibitive $(P)$ : beyond $6 \mathrm{~dB}$

Table 4: Major sources of uncertainty for compensated echo-level, source level (SL), transmission losses (TL), insonified area (A), and seafloor incidence angle. See the code $(N-S-M-H-P)$ definition in the text. Uncertainties are categorized as Bias or Random uncertainty based on their effect on the measurement.

\begin{tabular}{|c|c|c|c|c|c|}
\hline $\begin{array}{l}\text { Measurement } \\
\text { component }\end{array}$ & First-order uncertainty sources & Bias & Random & Magnitude & $\begin{array}{l}\text { Possible quality } \\
\text { improvement }\end{array}$ \\
\hline \multirow[t]{4}{*}{$\begin{array}{l}\text { Compensated } \\
\text { Echo Level }\end{array}$} & Signal fluctuations & & $\checkmark$ & $\begin{array}{l}M \text { to } H(5.57 d B \\
\text { std.dev. for a } \\
\text { Rayleigh distrib.) }\end{array}$ & $\begin{array}{l}\text { Decreased (S) by } \\
\text { data averaging (at } \\
\text { the expense of } \\
\text { resolution) }\end{array}$ \\
\hline & Noise Level & & $\checkmark$ & $S$ in most cases & $\begin{array}{l}\text { Improve sonar } \\
\text { performance }\end{array}$ \\
\hline & $\begin{array}{l}\text { Sonar parameters (without } \\
\text { calibration) }\end{array}$ & $\checkmark$ & & $\begin{array}{l}\text { Unpredictable - } \\
\text { up to } P\end{array}$ & Calibration \\
\hline & $\begin{array}{l}\text { Sonar parameters (after } \\
\text { calibration) }\end{array}$ & & $\checkmark$ & $N$ to $S$ & Calibration accuracy \\
\hline \multirow[t]{2}{*}{ Incidence angle } & Seafloor slope (compensated) & $\checkmark$ & $\checkmark$ & $N$ to $M$ & $\begin{array}{l}\text { Bathymetry DTM } \\
\text { accuracy }\end{array}$ \\
\hline & Seafloor slope (ignored) & $\checkmark$ & $\checkmark$ & $\begin{array}{l}N \text { to } P \text { according } \\
\text { to topography }\end{array}$ & $\begin{array}{l}\text { DTM for slope } \\
\text { compensation }\end{array}$ \\
\hline \multirow[t]{4}{*}{ Area (A) } & Footprint model approximation & $\checkmark$ & & $N$ to $S$ & - \\
\hline & $\begin{array}{l}\text { Incidence angle (refraction, } \\
\text { seafloor slope) }\end{array}$ & $\checkmark$ & $\checkmark$ & $\begin{array}{l}\text { S to M. Possibly } \\
\text { H to P (if } \\
\text { seafloor slope } \\
\text { ignored) }\end{array}$ & $\begin{array}{l}\text { Improved accuracy in } \\
\text { SVP and DTM }\end{array}$ \\
\hline & Sonar parameters & $\checkmark$ & & $S$ & $\begin{array}{l}\text { Constructor's } \\
\text { information }\end{array}$ \\
\hline & Propagation range & & $\checkmark$ & $N$ & - \\
\hline \multirow[t]{3}{*}{$\begin{array}{l}\text { Transmission } \\
\text { Loss (TL) }\end{array}$} & Absorption coefficient & $\checkmark$ & & $S$ to $H$ & $\begin{array}{l}\text { Water column } \\
\text { absorption profile }\end{array}$ \\
\hline & Propagation range & & $\checkmark$ & $N$ & - \\
\hline & Frequency differences (ignored) & $\checkmark$ & & $N$ to $M$ & $\begin{array}{l}\text { Sector frequency } \\
\text { accounted for }\end{array}$ \\
\hline
\end{tabular}




\section{Conclusions}

This work has attempted to identify and model the major causes and magnitudes of backscatter uncertainties from MBES systems. Unraveling the complexities of backscatter measurements is a considerable task, and the approach outlined here is far from complete; however, it is hoped that it offers a framework from which further understanding of the sources and magnitude of backscatter uncertainties can be derived.

The elementary uncertainty analysis proposed here identified the major components of the uncertainty budget (Tab. 4):

- The uncertainty in fluctuating and unreferenced measured echo levels is due to both the random character of the echo intensity (causing noise-like fluctuations to be processed statistically) and the incomplete knowledge of the MBES calibration parameters (leading to biases). The statistical uncertainty can be controlled by averaging a number of samples into a mean echo level with the understanding that increasing this number degrades resolution and thus a trade-off has to be made between resolution and uncertainty. In contrast, the uncertainty stemming from inaccurate values of MBES characteristics can reach unpredictable and unacceptable magnitudes if appropriate calibration operations have not been conducted nor reference data collected. MBES manufacturers should play a key role in addressing this issue by providing the information needed to better document and reduce this fundamental component of uncertainty, which is difficult to detect in the field data and whose accurate evaluation is rarely accessible to users.

- The uncertainty in seafloor incidence angle measurement is mostly affected by seafloor slope uncertainty controlled by the resolution and accuracy of bathymetric data used for DTM production (if used at all). Greater attention must be placed on the incorporation of bidimensional slope compensation inside the backscatter data processing tools and on the improvement of local slope determination from the bathymetry data. This uncertainty obviously impacts the computation of the backscatter angular response. Moreover, if not accounted for, slope is often the major cause of error in the insonified area computation. The sounder characteristics are normally sufficiently well known for the impact of their uncertainty to remain acceptable; this again falls under the manufacturer's responsibility.

- The transmission loss uncertainty is almost exclusively due to the absorption coefficient estimation, the inaccurate estimation of which can have a significant impact on the backscatter level estimation; however the combination of the measurement of temperature and salinity values over the full water column with appropriate procedures for compensation can keep the impact of the absorption coefficient within acceptable limits. The impact of local perturbations of the water column properties is not well-understood and deserves further investigation, although the use of ocean atlas data or ocean models can help to 
mitigate this problem. Unexpected phenomena such as bubble clouds sweeping the MBES arrays cause specific issues that are impossible to quantify in advance; however their joint impact on the objective quality of bathymetry data can help detect their presence and justify to disregard corrupted data.

This study was conducted as an initial step in the identification of the fundamental causes and estimation of order-of-magnitude levels of the uncertainties associated with the collection of MBES backscatter data. It has shown that it is difficult to predict broadly applicable numerical values, since many of the major uncertainty sources vary on a case-to-case basis. Future efforts need to be directed towards better provision of sonar characteristics from the manufacturers, improvement of MBES calibration methods, and quantification of their reliability and objective uncertainty. A second area of investigation is the impact of unexpected perturbations of the seawater column properties (e.g. bubble clouds). Both topics suggest the need for new welldesigned field experiments and would benefit greatly from collaborative efforts of the concerned communities.

\section{Acknowledgements}

Authors wish to thank two anonymous reviewers whose comments improved the manuscript significantly. The study was partly supported by NOAA awards NA17OG2285, NA16RP1718, NA04OAR4600155, NAOS4001153, ONR award N00014-00-1-0092 and IFREMER Foreign Fellow scientist grant.

\section{Disclaimer}

The scientific results and conclusions, as well as any views or opinions expressed herein, are those of the author(s) and do not necessarily reflect the views of NOAA or the Department of Commerce. Mention of a commercial company or product does not constitute an endorsement by NOAA.

\section{References}

Ainslie MA, McColm JG (1998) A simplified formula for viscous and chemical absorption in sea water. Journal of the Acoustical Society of America, 103(3): 1671-1672 https://doi.org/10.1121/1.421258

Alevizos E, Snellen M, Simons D, Siemes K, Greinert J (2017) Multi-angle backscatter classification and sub-bottom profiling for improved seafloor characterization, in Lamarche, G., and Lurton, X. (Eds) Seafloor backscatter data from swath mapping echosounders: From technological development to novel applications, Marine Geophysical Research https://doi.org/10.1007/s11001-017-9325-4

Anderson JT, Holliday DV, Kloser RJ, Reid D, Simard Y (Ed.) (2007). Acoustic seabed classification of marine physical and biological landscapes. ICES Cooperative Research Report No 286; 183 pp ISBN 87-7482-058-3 
Augustin JM, Lurton X (2005) Image amplitude calibration and processing for seafloor mapping sonars. Oceans 2005 - Europe, 1, 698-701 Vol 1 https://doi.org/10.1109/OCEANSE.2005.1511799

Beaudoin J, Hiebert J, Calder B, Imahori G (2009) Uncertainty Wedge Analysis: Quantifying the impact of Sparse Sound Speed Profiling Regimes on Soudning Uncertainty. Center For Coastal and Ocean Mapping Paper 453, U.S. Hydrographic Conference

Beaudoin J, Johnson P, Lurton X, Augustin JM (2012) R/V falkor multibeam echosounder system review UNH-CCOM/JHC Technical Report 12-001 September 4, 2012 57p http://mac.unols.org/sites/mac.unols.org/files/20120904_Falkor_EM710_EM302_report.pdf Last accessed June 2017

Bjørnø L (2017) Applied Underwater Acoustics, Neighbors TH, Bradley D (Eds) First edition. Amsterdam, Netherlands. Elsevier, ISBN-13: 978-0128112403

Brown CJ, Smith SJ, Lawton P, Anderson JT (2011) Benthic habitat mapping: A review of progress towards improved understanding of the spatial ecology of the seafloor using acoustic techniques. Estuarine, Coastal and Shelf Science, 92(3): 502-20 https://doi.org/10.1016/j.ecss.2011.02.007

Brown CJ, Schmidt V, Malik M, Bouffant N (2015) Backscatter measurement by bathymetric echo sounders. Report Chapter. Lurton X, Lamarche G (Eds) (2015) Backscatter measurements by seafloor-mapping sonars. Guidelines and Recommendations. 200p http://geohab.org/wpcontent/uploads/2013/02/BWSG-REPORT-MAY2015.pdf Last accessed June 2017

Calder B, Mayer L (2003) Automatic processing of high-rate, high-density multibeam echosounder data. Geochemistry, Geophysics, Geosystems, 4(6): 1048:1-22. https://doi.org/10.1029/2002GC000486

Chu D, Hufnagle LC (2006) Time varying gain (TVG) measurements of a multibeam echo sounder for applications to quantitative acoustics. In IEEE/OCEANS 2006 (pp 1-5). September 18-21, Boston, MA, USA https://doi.org/10.1109/OCEANS.2006.306818

Demer DA, Berger L, Bernasconi M, Bethke E, Boswell K, Chu D, Domokos R, et al. (2015) Calibration of acoustic instruments. ICES Cooperative Research Report No. 326. 133 pp.

De Moustier C, Alexandrou D (1991) Angular dependence of 12-kHz seafloor acoustic backscatter. The Journal of the Acoustical Society of America, 90(1): 522-531 https://doi.org/10.1121/1.401278

Diesing M, Mitchell P, Stephens D (2016) Image-based seabed classification: what can we learn from terrestrial remote sensing?, ICES Journal of Marine Science, 73(10):24252441 https://doi.org/10.1093/icesjms/fsw118 
Dolan MF, Lucieer VL (2014) Variation and uncertainty in bathymetric slope calculations using geographic information systems. Marine Geodesy, 37(2): 187-219 https://doi.org/10.1080/01490419.2014.902888

Doonan J, Coombs R, McClatchie S (2003) The absorption of sound in seawater in relation to the estimation of deep-water fish biomass. ICES Journal of Marine Science, 60(5): 1047-1055 https://doi.org/10.1016/S1054-3139(03)00120-6

Dyer I (1970) Statistics of sound propagation in the ocean. The Journal of the Acoustical Society of America, 48(1B): 337-345 https://doi.org/10.1121/1.1912133

Eleftherakis D, Berger L, Le Bouffant N, Pacault A, Augustin JM, Lurton X (2018) Backscatter calibration of high-frequency multibeam echosounder using a reference single-beam system, on natural seafloor, in Lamarche, G., and Lurton, X. (Eds) Seafloor backscatter data from swath mapping echosounders: From technological development to novel applications, Marine Geophysical Research (in press)

Fonseca L, Calder B, and Wetzler M (2006) Experiments for Multibeam Backscatter adjustments on the NOAA ship Fairweather. In IEEE/OCEANS 2006. September 18-21, Boston, MA, USA https://doi.org/10.1109/OCEANS.2006.307085

Fonseca L, Mayer L (2007) Remote estimation of surficial seafloor properties through the application of Angular Range Analysis to multibeam sonar data. Marine Geophysical Researches, 28(2), 119-126 https://doi.org/10.1007/s11001-007-9019-4

Fonseca L, Brown C, Calder B, Mayer L, Rzhanov Y (2009) Angular range analysis of acoustic themes from Stanton Banks Ireland: A link between visual interpretation and multibeam echosounder angular signatures. Applied Acoustics, 70(10): 1298-1304 https://doi.org/10.1016/j.apacoust.2008.09.008

Foote KG, Chu D, Hammar TR, Baldwin KC, Mayer LA, Hufnagle Jr LC, Jech JM (2005) Protocols for calibrating multibeam sonar. The Journal of the Acoustical Society of America, 117(4): 2013-2027 https://doi.org/10.1121/1.1869073

Francois RE, Garrison GR (1982) Sound absorption based on ocean measurements. Part II: Boric acid contribution and equation for total absorption. The Journal of the Acoustical Society of America, 72(6): 1879-1890 https://doi.org/10.1121/1.388673

Fusillo L, De Moustier C, Satriano JH, Zietz S (1996) In-situ far-field calibration of multibeam sonar arrays for precise backscatter imagery. In OCEANS MTS/IEEE September 23-26. Fort Lauderdale FL USA https://doi.org/10.1109/OCEANS.1996.566716

Gallaudet TC (2001) Shallow Water Acoustic Backscatter and Reverberation Measurements using a 68-kHz Cylindrical Array. PhD Dissertation. University of Califonia, San Diego. Chapter 
3, Using Environmental Information to correct for errors in Bathymetry and Seafloor Acoustic Backscattering Strength Imagery

Gavrilov AN, Parnum IM (2010) Fluctuations of seafloor backscatter data from multibeam sonar systems. IEEE Journal of Oceanic Engineering, 35(2): 209-219

https://doi.org/10.1109/JOE.2010.2041262

Greenaway SF, Weber TC (2010) Test methodology for evaluation of linearity of multibeam echosounder backscatter performance. In OCEANS 2010 September 20-23. Seattle WA USA https://doi.org/10.1109/OCEANS.2010.5664383

Hammerstad E (2000) EM technical note: Backscattering and seabed image reflectivity. Kongsberg Maritime AS, Horten Available online at: https://www.km.kongsberg.com/ks/web/nokbg0397.nsf/AllWeb/C2AE0703809C1FA5C1257B5 80044DD83/\$file/EM_technical_note_web_BackscatteringSeabedImageReflectivity.pdf Last accessed January 2018

Hare R, Godin A, Mayer LA (1995) Accuracy estimation of Canadian swath (multibeam) and sweep (multitransducer) sounding systems. Technical report, Canadian Hydrographic Service and University of New Brunswick, Fredericton

Hare R (2001) Error budget analysis for US Naval Oceanographic Office (NAVOCEANO) hydrographic survey systems. University of Southern Mississippi, Hydrographic Science Research Center for the Naval Oceanographic Office

Hasan RC, Lerodiaconou D, Laurenson L, Schimel A (2014) Integrating multibeam backscatter angular response, mosaic and bathymetry data for benthic habitat mapping. PLOS one 9(5): e97339 https://doi.org/10.1371/journal.pone.0097339

Hauser O, Downs R, Rice G, Greenaway S, Annis M, Eisenberg J, Malik M (2015) NOAA's Multibeam Sonar Test Procedure Manual: Formalizing and documenting a procedure to ensure that a new multibeam sonar is properly installed, integrated, and capable of meeting hydrographic standards. US Hydrogrpahic Conference, March 16-19, Washington DC USA

Heaton J, Weber T, Rice G, Lurton X (2013) Testing of an extended target for use in high frequency sonar calibration. Proceedings of Meetings on Acoustics 19(1) https://doi.org/10.1121/1.4800927

Hellequin, L, Boucher JM, Lurton X (2003) Processing of high-frequency multibeam echo sounder data for seafloor characterization. IEEE Journal of Oceanic Engineering, 28(1): 78-89 https://doi.org/10.1109/JOE.2002.808205 
Hiroji A (2016) Extracting sonar relative along-track and Across-track radiometric beam pattern for multi-sector multi-swath multibeam sonars, $\mathrm{PhD}$ dissertation. The University of New Brunswick

Hughes Clarke JE, Mayer LA, Wells DE (1996) Shallow-water imaging multibeam sonars: a new tool for investigating seafloor processes in the coastal zone and on the continental shelf. Marine Geophysical Researches, 18(6): 607-629 https://doi.org/10.1007/BF00313877

Hughes Clarke JE, Danforth BW, Valentine P (1997) Areal seabed classification using backscatter angular response at $95 \mathrm{kHz}$. In NATO SACLANTCEN Undersea Research Centre Conference on High Frequency Acoustics in Shallow Water (pp 243-250) June 30 - July 4, Lerici, Italy

Hughes Clarke JE (2012) Optimal use of multibeam technology in the study of shelf morphodynamics, in Sediments, Morphology and Sedimentary Processes on Continental Shelves: Advances in Technologies, Research and Applications (eds Li MZ, Sherwood CR, and Hill PR), John Wiley \& Sons, Ltd, Chichester, West Sussex, UK http://doi.org/10.1002/9781118311172.ch1

IHO (International Hydrographic Organization) (2008) IHO Standards for Hydrographic Surveys Special publication no 44, $5^{\text {th }}$ edition www.iho.int/iho_pubs/standard/S-44_5E.pdf Last accessed June 2017

Jackson D, Richardson M (2007) High-frequency seafloor acoustics. New York NY USA: Springer Science \& Business Media https://doi.org/10.1007/978-0-387-36945-7

Johannesson KA, Mitson RB (1983) Fisheries acoustics. A practical manual for aquatic biomass estimation. FAO Fish. Tech. Pap. vol.240. 249 pp.

Kim YS, Moore RK, Onstott RG (1982) Scattering Coefficient Estimation: An Examination of the Narrow-Beam Approximation (No RSL-TR-331-23). Kansas University Remote Sensing Lab /Center for Research Inc. Technical Report, August 38 pp

Lacharité M, Brown CJ, Gazzola V (2017) Multisource multibeam backscatter data: developing a strategy for the production of benthic habitat maps using semi-automated seafloor classification methods, in Lamarche, G., and Lurton, X. (Eds) Seafloor backscatter data from swath mapping echosounders: From technological development to novel applications, Marine Geophysical Research https://doi.org/10.1007/s11001-017-9331-6

Ladroit Y, Sintes C, Lurton X, Garello R (2012) Extended scatterers model for fast sonar signal simulation. In IEEE Oceans Conference, May 21-24 Yeosu, Republic of Korea https://doi.org/10.1109/OCEANS-Yeosu.2012.6263487 
Ladroit Y, Lamarche G, Pallentin A (2018) Seafloor multibeam backscatter calibration experiment: comparing $45^{\circ}$-tilted 38-kHz split-beam echosounder and 30-kHz multibeam data, in Lamarche G, and Lurton, X. (Eds) Seafloor backscatter data from swath mapping echosounders: From technological development to novel applications, Marine Geophysical Research, https://doi.org/10.1007/s11001-017-9340-5

Lamarche G, Lurton X, Verdier A L, Augustin J M (2011) Quantitative characterisation of seafloor substrate and bedforms using advanced processing of multibeam backscatterApplication to Cook Strait, New Zealand. Continental Shelf Research, 31(2):S93-S109 https://doi.org/10.1016/j.csr.2010.06.001

Lamarche G, Lurton X (2017) Recommendations for improved and coherent acquisition and processing of backscatter data from seafloor-mapping sonars, in Lamarche, G., and Lurton, X. (Eds) Seafloor backscatter data from swath mapping echosounders: From technological development to novel applications, Marine Geophysical Research https://doi.org/10.1007/s11001-017-9315-6

Lanzoni C, Weber T (2011) A Method for Field Calibration of a Multibeam Echo Sounder. In Oceans MTS/IEEE September 19-22 Kona HI, USA

https://doi.org/10.23919/OCEANS.2011.6107075

Lehaitre, M, Delauney L, Compère C (2008) Biofouling and underwater measurements, in Babin M, Roesler CS, Cullen JJ (Eds) Real-time observation systems for ecosystem dynamics and harmful algal blooms: Theory, instrumentation and modelling. Oceanographic Methodology Series. UNESCO, Paris, 463-493

Llewellyn, KC (2006) Corrections for beam pattern residuals in backscatter imagery from the Kongsberg Simrad EM300 Multibeam Echosounder. MS Thesis. University of New Brunswick Ocean Mapping Group

Long DG, Skouson GB (1996) Calibration of spaceborne scatterometers using tropical rain forests. IEEE Transactions on Geoscience and Remote Sensing, 34(2): 413-424 https://doi.org/10.1109/36.485119

Lucieer V, Huang Z, Siwabessy J (2015) Analysing Uncertainty in Multibeam Bathymetric Data and the Impact on Derived Seafloor Attributes, Marine Geodesy 39(1): 32-52 https://doi.org/10.1080/01490419.2015.1121173

Lucieer, V., Roche, M., Degrendele, K., Malik, M., Dolan, M. and Lamarche, G. (2017) User expectations for multibeam echo sounders backscatter strength data - Looking back into the future, in Lamarche, G., and Lurton, X. (Eds) Seafloor backscatter data from swath mapping echosounders: From technological development to novel applications, Marine Geophysical Research https://doi.org/10.1007/s11001-017-9316-5 
870 - Lurton X (2010) An Introduction To Underwater Acoustics - Principles and Applications,

871 Second Edition, Springer-Verlag, Berlin ISBN 978-3-540-78480-7

872

873 Lurton X, Augustin JM (2010) A Measurement Quality Factor for Swath Bathymetry Sounders.

874 IEEE Journal Of Oceanic $\quad$ Engineering, $352-862$

875 https://doi.org/10.1109/JOE.2010.2064391

876 Lurton X, Lamarche G (eds) (2015) Backscatter measurements by seafloor-mapping sonars.

877 Guidelines and Recommendations. 200p. http://geohab.org/wp-

878 content/uploads/2014/05/BSWGREPORT-MAY2015.pdf Last accessed June 2017

879 Lurton X, Eleftherakis D, Augustin JM (2017) Analysis of seafloor backscatter strength 880 dependence on the survey azimuth using multibeam echosounder data, in Lamarche, G., and 881 Lurton, X. (Eds) Seafloor backscatter data from swath mapping echosounders: From 882 technological development to novel applications, Marine Geophysical Research 883 https://doi.org/10.1007/s11001-017-9318-3

884 Matsumoto H, Dziak RP, Fox CG (1993) Estimation of seafloor microtopographic roughness 885 through modeling of acoustic backscatter data recorded by multibeam sonar systems. The 886 Journal of the Acoustical Society of America, 94(5): 2776-2787 887 https://doi.org/10.1121/1.407361

888 Mayer LA (2006) Frontiers in seafloor mapping and visualization. Marine Geophysical 889 Researches, 27(1): 7-17 https://doi.org/10.1007/s11001-005-0267-X

890 Mandell J (1964) The statistical analysis of experimental data. Dover Publications, Inc., New 891 York, USA

892 Parnum IM, Gavrilov AN (2011) High-frequency multibeam echo-sounder measurements of 893 seafloor backscatter in shallow water: Part 1-Data acquisition and processing. Underwater 894 Technology, 30(1): 3-12 https://doi.org/10.3723/ut.30.003

895 Peritsky MM (1973) Statistical estimation of mean signal strength in a Rayleigh fading 896 environment. IEEE transactions on communication, 21(11): 1207-1213

897 https://doi.org/10.1109/TCOM.1973.1091577

898 Prigent C, Aires F, Jimenez C, Papa F, Roger J (2015) Multiangle backscattering observations of 899 continental surfaces in $\mathrm{Ku}-\mathrm{Band}(13 \mathrm{GHz})$ from satellites: understanding the signals, particularly 900 in arid regions. IEEE Transactions on Geoscience and Remote Sensing, 53(3): 1364-1373 901 https://doi.org/10.1109/TGRS.2014.2338913

902 QPS Technical note (2014) Technical note 1: Correcting backscatter for seafloor 3D incidence.

903 Available online at: 
https://confluence.qps.nl/display/KBE/Technical+Note+1\%3A+Correcting+backscatter+for+seaf loor+3D+incidence Last accessed June 2017

Reed T, Hussong D (1989) Digital image processing techniques for enhancement and classification of SeaMARC II side scan sonar imagery. Journal of Geophysical Research 94(B6): 7469-90 http://doi.org/10.1029/JB094iB06p07469

Rice G, Greenaway S, Weber T, Beaudoin J (2012) Methods for Collecting and Using Backscatter Field Calibration Information for the Reson 7000 Series Multibeams. Center for Coastal and Ocean Mapping. Paper 840. http://scholars.unh.edu/ccom/840 Last accessed June 2017

Rice G, Cooper R, Degrendele K, Gutierrez F, Le Bouffant N, Roche M (2015) Chapter 5 Acquisition: best practice guide. In: Lurton X, Lamarche G (eds) Backscatter measurements by seafloor-mapping sonars - Guidelines and Recommendations. Geohab report, 79-132 http://geohab.org/wp-content/uploads/2013/02/BWSG-REPORT-MAY2015.pdf Last accessed June 2017

Rice G, Malik M (2015) NOAA Ship Nancy Foster EM 710 Acceptance Testing with Hydrographic Systems and Technology Programs Multibeam sonar acceptance procedures, 9-13 March http://mac.unols.org/sites/mac.unols.org/files/NF_EM710_acceptance.pdf Last accessed June 2017

Rzhanov Y, Fonseca L, Mayer L (2012) Construction of seafloor thematic maps from multibeam acoustic backscatter angular response data. Computers \& Geosciences, 41: 181-187 https://doi.org/10.1016/j.cageo.2011.09.001

Schimel A, Beaudoin J, Gaillot A, Keith G, Le Bas T, Parnum I, Schmidt V (2015) Chap 6: Processing backscatter data: from datagrams to Angular responses and mosaics. In: Lurton X, Lamarche G (eds) Backscatter measurements by seafloor-mapping sonars - Guidelines and Recommendations. Geohab report, 133-164 http://geohab.org/wpcontent/uploads/2013/02/BWSG-REPORT-MAY2015.pdf Last accessed June 2017

Sea-Bird Electronics Inc. (2010) Application note no 6. Available online http://www.seabird.com/document/an06-determination-sound-velocity-ctd-data. Last accessed: February 2017

Simons DG, Snellen M (2009) A Bayesian approach to seafloor classification using multi-beam echo-sounder backscatter data. Applied Acoustics, 70(10): 1258-1268

https://doi.org/10.1016/j.apacoust.2008.07.013

Stanic S, Kennedy E (1992) Fluctuations of high-frequency shallow-water seafloor reverberation. The Journal of the Acoustical Society of America, 91(4): 1967-1973 https://doi.org/10.1121/1.403680 
Teng, Y (2011) Sector-specific beam pattern compensation for multi-sector and multi-swath multibeam sonars. MScE Thesis, Department of Geodesy and Geomatics Engineering, University of New Brunswick

Ulaby FT, Allen CT, Fung AK (1983) Method for retrieving the true backscattering coefficient from measurements with a real antenna. IEEE Transactions on Geoscience and Remote Sensing, GE-21(3): 308-313 https://doi.org/10.1109/TGRS.1983.350558

Urick RI (1983) Principles of underwater acoustics. McGraw-Hill, New York ISBN 0932146627

Wang Q, Gogineni SP (1991) A numerical procedure for recovering true scattering coefficients from measurements with wide-beam antennas. IEEE Transactions on Geoscience and Remote Sensing, 29(5): 778-783 https://doi.org/10.1109/36.83993

Welton B (2014) A Field Method for Backscatter Calibration Applied to NOAA's Reson 7125 Multibeam Echo-Sounders. MS Thesis. University of New Hampshire, Durham, NH, US

Zhu SJ, Tang GA, Xiong LY, Zhang G (2014) Uncertainty of slope length derived from digital elevation models of the Loess Plateau, China. Journal of Mountain Science 11(5): 1169-1181 https://doi.org/10.1007/s11629-013-2788-0

\section{APPENDIX A}

\section{Statistical uncertainty in measured $E L$}

The statistical fluctuation of the $E L$ is an inherent property of backscattered signals and therefore an unavoidable source of random uncertainty. However, confidence in the mean echo level reliability can be improved by increasing the number of samples used in averaging. In MBES data, this is done most often by averaging across-track and along-track samples. However, this should only be done for homogeneous seafloor as the mean angular response can be corrupted at the transition between two seafloor types. Mosaic segmentation into areas showing similar backscatter can help in selecting regions of the same seafloor type over which the samples can be averaged (Rzhanov et al. 2012). The number of samples available for each beam is controlled by the across-track footprint extent, so the largest number of samples is obtained for the outer-most beams. Assuming that the time series is being sampled at a high enough rate compared with the pulse duration, the number of statistically-independent samples $N_{s}$ inside a beam is computed as the ratio of the length of the receive beam footprint in the across-track direction and the projected pulse duration (Simons and Snellen 2009):

$$
N_{S}(\theta) \approx\left(\frac{z \omega}{\cos ^{2} \theta}\right) /\left(\frac{c T}{2 \sin \theta}\right)
$$

where $\mathrm{z}$ is the water depth, $\omega$ the $R x$ across-track beamwidth, $c$ the sound speed, $T$ the pulse length and $\theta$ the incidence angle. Eq. [A1] holds for long-pulse regime, excluding the angles 
around nadir. Obviously, the benefit of averaging over several samples exists only when $N_{s}>1$. Fig. A1 presents the number of statistically independent samples for a MBES with $\omega=0.5^{\circ}$ and $2^{\circ}$; and $\mathrm{z}=50 \mathrm{~m}$ (with $T=0.05 \mathrm{~ms}$ and $0.15 \mathrm{~ms}$ ) and $1000 \mathrm{~m}$ (with $T=5 \mathrm{~ms}$ and $10 \mathrm{~ms}$ ). $N_{s}$ increases with decreasing $T$ and increasing $\omega$.

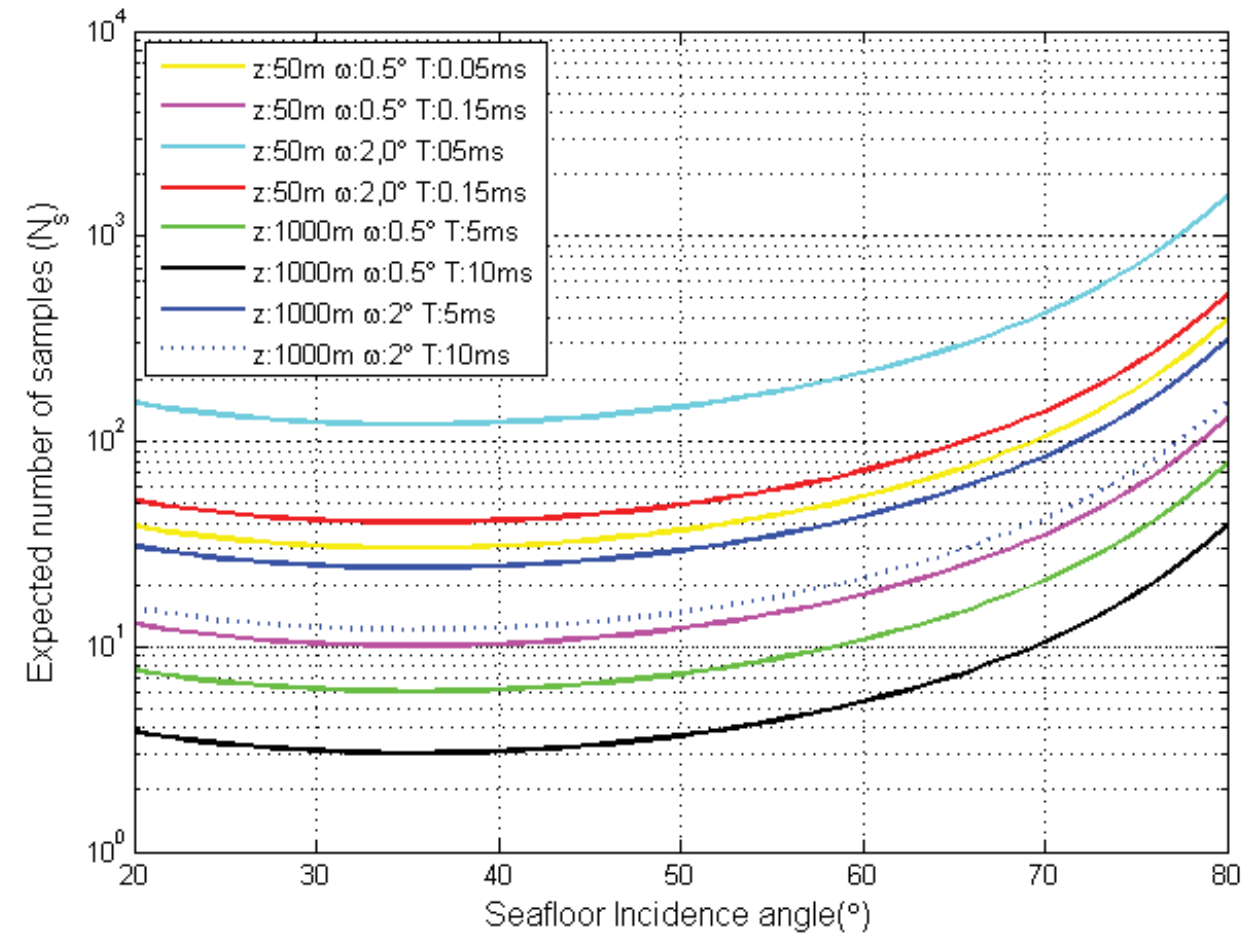

Figure A1: Estimated number [Eq. A1] of statistically independent samples for each beam for a multibeam echosounder at water depths $50 \mathrm{~m}$ and $1000 \mathrm{~m}$; beamwidths of $0.5^{\circ}$ and $2^{\circ}$; and pulse lengths $(0.15 ; 0.5$; 5 and $10 \mathrm{~ms})$.

The standard deviation of $N$ averaged independent samples is given as:

$$
\sigma_{\bar{x}}=\frac{\sigma_{x}}{\sqrt{N}}
$$

where $\sigma_{\bar{x}}$ and $\sigma_{x}$ are the standard deviations of averaged and individual samples respectively. Eq. [A2] is valid provided that the $N$ averaged values are statistically independent, are derived from a same population, and have the same variance (Mandell 1964). Assuming the standard deviation of individual samples is $5.57 \mathrm{~dB}$ (Rayleigh distribution) and averaging over the $\mathrm{dB}$ values, more than 30 individual samples are required to achieve a $1 \mathrm{~dB}$ standard deviation (Fig. A2). If the envelope squared amplitudes (i.e. intensity) in natural units is considered for the averaging (which is a preferable way to do it), the $\mathrm{dB}$ value of the standard deviation referenced to the 
mean is $10 \log _{10}(1+1 / \sqrt{N}) \approx 4.34 / \sqrt{N} \mathrm{~dB}$ (Bjørnø 2017 p. 527). In this case, to reduce the standard deviation to $1 \mathrm{~dB}$, only 20 samples are required (Fig. A2). Although the uncertainty is lowered by averaging over larger number of samples, the spatial resolution is adversely affected which may or may not be important depending on the type of application (compare high resolution mapping, with large scale mapping).

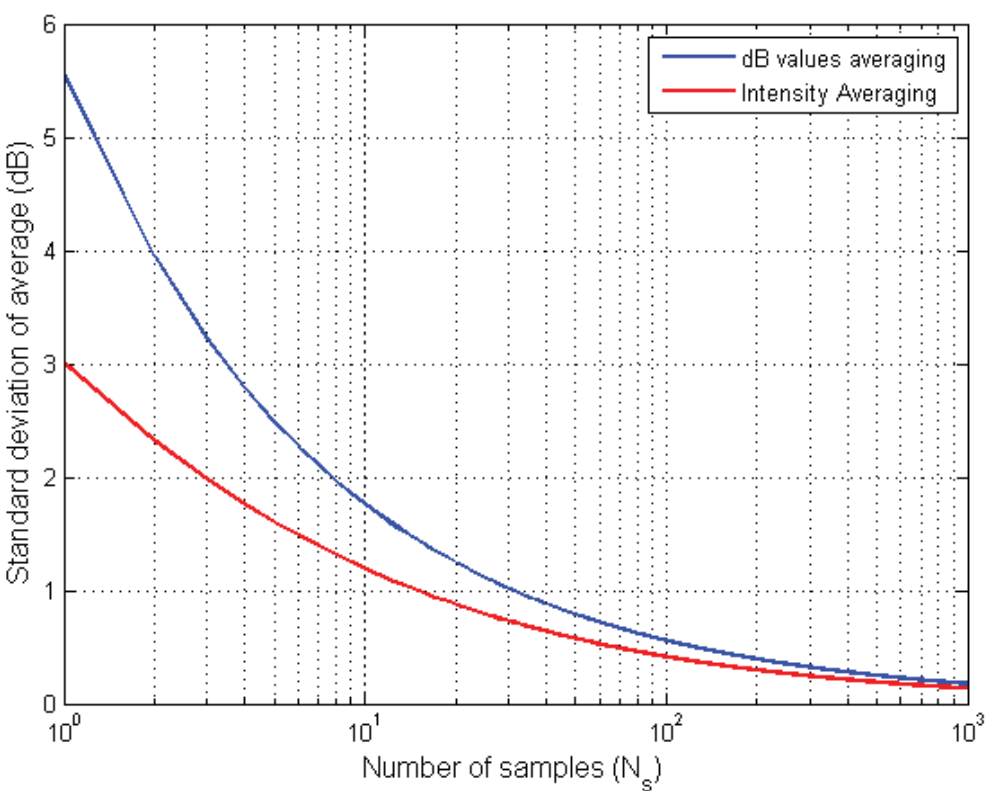

Figure A2: Estimated number of statistically independent samples to be averaged in order to obtain a given standard deviation (in dB). The initial distribution is Rayleigh, with a standard deviation of $5.57 \mathrm{~dB}$. 